\title{
P2Y6 signaling in alveolar macrophages prevents leukotriene-dependent type 2 allergic lung inflammation
}

\author{
Jun Nagai, ${ }^{1,2}$ Barbara Balestrieri, ${ }^{1,2}$ Laura B. Fanning, ${ }^{1,2}$ Timothy Kyin,,${ }^{1,2}$ Haley Cirka, ${ }^{2}$ Junrui Lin, ${ }^{2}$ Marco Idzko, ${ }^{3}$ Andreas Zech, ${ }^{3}$ \\ Edy Y. Kim, ${ }^{1,4}$ Patrick J. Brennan, ${ }^{1,2}$ and Joshua A. Boyce ${ }^{1,2,5}$ \\ 'Department of Medicine, Harvard Medical School, Boston, Massachusetts, USA. ${ }^{2}$ Jeff and Penny Vinik Center for Allergic Disease Research, Division of Rheumatology, Immunology and Allergy, Brigham and \\ Women's Hospital, Boston, Massachusetts, USA. ${ }^{3}$ Department of Pulmonology, Medical University of Vienna, Vienna, Austria. ${ }^{4}$ Division of Pulmonary Medicine, Brigham and Women's Hospital, Boston, \\ Massachusetts, USA. D. Department of Pediatrics, Harvard Medical School, Boston, Massachusetts, USA.
}

\begin{abstract}
Antagonists of the type 1 cysteinyl leukotriene receptor (CysLT $R$ ) are widely used to treat asthma and allergic rhinitis, with variable response rates. Alveolar macrophages express UDP-specific $P 2 Y_{6}$ receptors that can be blocked by off-target effects of CysLT ${ }_{1}$ antagonists. Sensitizing intranasal doses of an extract from the house dust mite Dermatophagoides farinae ( $D f$ ) sharply increased the levels of UDP detected in bronchoalveolar lavage fluid of mice. Conditional deletion of $P 2 Y_{6}$ receptors before sensitization exacerbated eosinophilic lung inflammation and type 2 cytokine production in response to subsequent $D f$ challenge. $P 2 Y_{6}$ receptor signaling was necessary for dectin-2-dependent production of protective IL-12p40 and Th1 chemokines by alveolar macrophages, leading to activation of NK cells to generate IFN- $\gamma$. Administration of CysLT $\mathrm{R}_{1}$ antagonists during sensitization blocked UDP-elicited potentiation of IL-12p40 production by macrophages in vitro, suppressed the $D f$-induced production of IL-12p40 and IFN- $\gamma$ in vivo, and suppressed type 2 inflammation only in P2Y $\mathrm{Y}_{6}$-deficient mice. Thus, P2Y $\mathrm{Y}_{6}$ receptor signaling drives an innate macrophage/IL-12/NK cell/IFN- $\gamma$ axis that prevents inappropriate allergic type 2 immune responses on respiratory allergen exposure and counteracts the Th2 priming effect of $C_{y s L T} R$ signaling at sensitization. Targeting $\mathrm{P}_{2} \mathrm{Y}_{6}$ signaling might prove to be a potential additional treatment strategy for allergy.
\end{abstract}

\section{Introduction}

Type 2 immunity (T2I) mediates host defense against helminthic parasites (1) and facilitates epithelial barrier repair (2). If dysregulated or directed against innocuous antigens (allergens), T2I can also promote persistent eosinophilic inflammation and disease. Allergens in house dust mites (HDMs), fungi, and pollens carry endogenous adjuvants (endotoxin, lipids, proteases, and glycans) that activate barrier cells and antigen-presenting cells through pattern recognition receptors $(3,4)$. This innate response bridges to adaptive T2I involving effector and memory $\mathrm{T}$ cells, antigen-specific IgE, and the production of the type 2 cytokines IL-4, IL-5, and IL-13 (5). T2I to allergens is strongly associated with increasingly prevalent diseases such as asthma, rhinosinusitis, and allergic esophagitis, each of which involves end-organ dysfunction and remodeling due to T2I-dependent immunopathology (6-8). Recent studies using cytokine-targeted therapies and anti-IgE validate the importance of the pathologic processes regulated by T2I in these diseases $(9,10)$. Checking the destructive potential of T2I requires the presence of mechanisms that ensure that the initial innate response to allergens is tightly regulated and compartmentalized. The basis of this regulation

Conflict of interest: The authors have declared that no conflict of interest exists. Copyright: () 2019, American Society for Clinical Investigation.

Submitted: April 23, 2019; Accepted: August 20, 2019; Published: October 22, 2019.

Reference information: / Clin Invest. 2019;129(12):5169-5186.

https://doi.org/10.1172/JCl129761. remains incompletely understood but likely involves components of the innate immune response that control the magnitude of subsequent T2I responses.

In addition to exogenous adjuvants, endogenous dangerassociated molecular patterns (DAMPs) (lipids, cytokines, and other extracellular signaling molecules) help to bridge innate to adaptive immunity. DAMPs derive from tissue-resident cells or recruited myeloid cells early following exposure to antigens (3, 11). They fine-tune signal strength and production of canonical cytokines by antigen-presenting cells, thus shaping instructions received by lymphoid effectors. Cysteinyl leukotrienes (cysLTs) are arachidonic acid-derived mediators generated by mast cells, eosinophils, DCs, and macrophages. In addition to their role as bronchoconstrictors in asthma $(12,13)$, they act as DAMPs that facilitate T2I through effects on DCs (3) and group 2 innate lymphoid cells (ILC2s) (14). These effects are mediated by the type 1 receptor for the cysLTs (CysLT $R$ ), a GPCR that is the target for the widely prescribed drugs montelukast, zafirlukast, and pranlukast. The therapeutic efficacy of these drugs for the treatment of asthma and allergic rhinitis varies, with as few as $24 \%$ to as many as $78 \%$ of patients failing to show symptomatic improvement (15, 16). The reasons for this variable response are not clear but may involve individual variation in the contributions from cysLTs to T2I (17), as well as potential off-target effects of the drugs at receptors that exert a protective role (18).

The purinergic receptor (P2Y) class of GPCRs is a potential unintended target of $\mathrm{CysLT}_{1} \mathrm{R}$ antagonists. P2Y receptors recog- 
nize extracellular nucleotides (19), are structurally homologous to CysLT $_{1} \mathrm{R}(20)$, and are blocked in vitro by CysLT ${ }_{1}$ R antagonists (21). $\mathrm{P} 2 \mathrm{Y}$ receptors, along with nucleotide-selective ion channels ( $\mathrm{P} 2 \mathrm{X}$ receptors), mediate DAMP-like effects of nucleotides in T2I. ATP is released at high levels in the airways of asthmatic subjects challenged with allergen (22). ATP primes lung DCs to promote T2I to the innocuous experimental antigen ovalbumin (22) and acts at $\mathrm{P} 2 \mathrm{Y}_{2}$ receptors on respiratory epithelial cells to induce the release of IL-33, a T2I-promoting alarmin (4). Less is understood about the roles of UTP and UDP (23), the latter of which preferentially binds $\mathrm{P} 2 \mathrm{Y}_{6}$ receptors (24). $\mathrm{P}_{2} \mathrm{Y}_{6}$ receptors are expressed by bronchial epithelial cells during pathologic mucosal inflammation $(25,26)$ and are also expressed strongly and constitutively by monocytes, macrophages, and DCs (27) (http://rstats.immgen.org/Skyline/ skyline.html). Because $\mathrm{P} 2 \mathrm{Y}_{6}$ receptors exhibit the highest affinity (nM range) (28) of all $\mathrm{P} 2 \mathrm{Y}$ receptors for their cognate ligand, these cells may be highly sensitive to changes in the local levels of UDP. P2Y 6 receptor signaling facilitates proinflammatory chemokine and cytokine production through both autocrine and paracrine circuits in several cell types ex vivo $(26,29,30)$, but its role in T2I is unclear. Selective $\mathrm{P}_{2} \mathrm{Y}_{6}$ receptor blockade decreases allergeninduced lung eosinophil counts and type 2 cytokine production in immunologically sensitized mice (26). In contrast, induced deletion of $\mathrm{P}_{2} \mathrm{Y}_{6}$ receptors markedly enhances pulmonary T2I responses of mice to repetitive inhalation challenges with an extract $(D f)$ of the clinically important HDM Dermatophagoides farinea (31), and a selective $\mathrm{P} 2 \mathrm{Y}_{6}$ receptor agonist prevented the development of airway hyperresponsiveness and inflammation in a mouse asthma model (32). These studies suggest a complex, context-specific function of UDP and $\mathrm{P} 2 \mathrm{Y}_{6}$ receptors that may either protect from or promote T2I in the lung.

In this study, we sought to identify key steps and cell types responsible for the protective effect of $\mathrm{P} 2 \mathrm{Y}_{6}$ receptors and their preferred ligand, UDP, in pulmonary T2I; to resolve the potentially contradictory effects of $\mathrm{P}_{2} \mathrm{Y}_{6}$ receptor signaling in different models of allergen-induced pulmonary inflammation; and to determine the potential consequences of $\mathrm{P} 2 \mathrm{Y}_{6}$ receptor block-

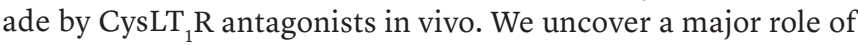
$\mathrm{UDP} / \mathrm{P} \mathrm{Y}_{6}$ receptor signaling in controlling a previously unrecognized protective function of alveolar macrophages (AMs). This function was mediated by IL-12-dependent activation of an innate, NK cell-dependent IFN response that dampened subsequent $D f$-induced T2I. We also demonstrate that the protective $\mathrm{P} 2 \mathrm{Y}_{6}$ response is blocked by antagonists of $\mathrm{CysLT}_{1} \mathrm{R}$ in vivo and counterbalances the established pro-T2I role of CysLT $\mathrm{R}_{1} \mathrm{R}$ signaling at sensitization (33).

\section{Results}

Deletion of $\mathrm{P} 2 \mathrm{Y}_{6}$ at sensitization, but not at challenge, amplifies pulmonary type 2 responses to $D f . P 2 r y 6^{f / f / / C r e /+}$ mice, which were generated from $P 2 r y 6^{f l / f l}$ and Rosa26-CreER $R^{T 2}$ mice, display increased T2I and associated eosinophilic pulmonary inflammation compared with $P 2 r y 6^{f / f l /+/+}(+/+)$ controls when subjected to repetitive administration of low-dose $(3 \mu \mathrm{g}) \mathrm{D} f$ over a 3-week period (31). To distinguish the potential contributions of UDP and $\mathrm{P} 2 \mathrm{Y}_{6}$ receptors to the respective sensitization and effector steps of the $D f$-induced T2I, we modified the protocol to incorporate distinct sensitiza- tion and challenge phases (Figure $1 \mathrm{~A}$ ). Both $+/+$ and $P 2 r y 6^{f / f / / \mathrm{Cr} /+}$ mice were treated with tamoxifen daily i.p. for 5 days, beginning 14 days before the first $D f$ exposure, to delete the P2ry6 allele prior to sensitization. Mice received sensitizing i.n. doses $(20 \mu \mathrm{g})$ of $D f$ on successive days (days 0 and 1 ), followed by challenges with low-dose $D f(3 \mu \mathrm{g})$ on days 14 and 15 , or they received equal volumes of $\mathrm{NaCl}$. BAL fluid and tissues were collected 16 hours after the last challenge dose. Tamoxifen induced $80 \%-90 \%$ deletion of the P2ry6 transcript in the lung, spleen, BM, paratracheal lymph nodes, and BAL fluid cells of the P2ry $6^{f / f / / \mathrm{Cre} /+}$ mice (Supplemental Figure 1A; supplemental material available online with this article; https://doi.org/10.1172/JCI129761DS1). Quantitative PCR (qPCR) of AMs (CD11c ${ }^{+}$BAL fluid cells) sorted from P2ry $6^{f / / f / / \mathrm{Cr} /+}$ mice demonstrated an $84 \%$ decrease in expression of the floxed $\mathrm{P}_{2} \mathrm{Y}_{6}$ (exon 3) allele, indicating that more than $80 \%$ recombination had occurred (Supplemental Figure 1B). BM-derived macrophages (BMMs) from $+/+$ mice showed marked dose-dependent increases in intracellular calcium levels in response to stimulation with UDP that were attenuated in macrophages derived from the BMs of $P 2 r y 6^{f / f / / C r e /+}$ mice (Supplemental Figure $1 \mathrm{C}$ ). Both BMMs and DCs and from +/+ mice displayed rapid decreases (3 hours) in P2ry6 mRNA expression in response to stimulation with $D f$ (Supplemental Figure 1D).

To determine whether the deletion of $\mathrm{P}_{2} \mathrm{Y}_{6}$ receptors prior to sensitization enhanced $D f$-induced T2I in the modified protocol, we examined BAL fluid for cell counts and mediators on day 16 (16 hours after the second challenge dose of $D f$ ) and for type 2 cytokines. Whereas $D f$-sensitized and -challenged $+/+$ mice displayed minimal to negligible BAL fluid eosinophilia and neutrophilia, $P 2 r y 6^{f / f / / C r e /+}$ mice showed significant increases in BAL fluid total cell, eosinophil, neutrophil, and AM/lymphocyte counts (Figure 1B). The level of BAL fluid eosinophilia observed in $+/+$ mice in this $D f$ protocol (2 sensitizing doses followed by 2 challenges 14 days later) was lower than that induced by the repetitive $D f$ protocol used in the previous study (6 i.n. doses over 18 days) (31). H\&Estained lung sections revealed negligible bronchovascular cellular infiltrates in $D f$-treated $+/+$ controls but substantial infiltrates in P2ry $6^{f / f l / C r e /+}$ mice (Figure 1C). Levels of IL-4, IL-5, IL-13, eosinophil peroxidase (EPO), and myeloperoxidase (MPO) were higher in BAL fluid of $D f$-sensitized and -challenged $P 2 r y 6^{f / f / / \mathrm{Cre} /+}$ mice than $+/+$ controls (Figure 1D and Supplemental Figure 2A). qPCR revealed significantly greater expression of $I l 4, I l 5$, and $I l 13 \mathrm{mRNA}$ by lungs of $D f$-treated $P 2 r y 6^{f / f / / / C r e /+}$ mice than +/+ controls; and of Il33, and the goblet cell transcript Clca3, as well as Epx (encoding $\mathrm{EPO}$ ) and Rnase2 (consistent with the presence of eosinophils); but not of Tslp and Il25 (Supplemental Figure 2, B and C). Serum levels of total IgE rose in both the $D f$-sensitized and -challenged $P 2 r y 6^{f / f / / C r /+}$ mice and $+/+$ controls (they tended to be higher in $P 2 r y 6^{f / f / / \mathrm{Cre} /+}$ mice; median $+/+D f: 1.32 \mu \mathrm{g} / \mathrm{mL} n=29, P 2 r y 6^{f / f / / \mathrm{Cr} /+}$ Df: $2.76 \mu \mathrm{g} / \mathrm{mL} n=27$ ), whereas IgG2c (a Th1-related antibody isotype in C57BL/6 mice) increased only in the $D f$-challenged +/+ mice, and IgM levels did not change (Figure 1E and Supplemental Figure 2D). Whole-lung Ifng mRNA expression levels and BAL fluid IFN- $\gamma$ levels were similarly low in the Df- and NaCl-treated mice, and did not differ between strains (Supplemental Figure 2E). The enhanced type 2 cytokine (IL-4, IL-5, and IL-13) production reflected increased numbers of cytokine-expressing $\mathrm{T}$ cells $\left(\mathrm{CD}^{+} \mathrm{CD}^{+} \mathrm{O}^{+}\right)$in 

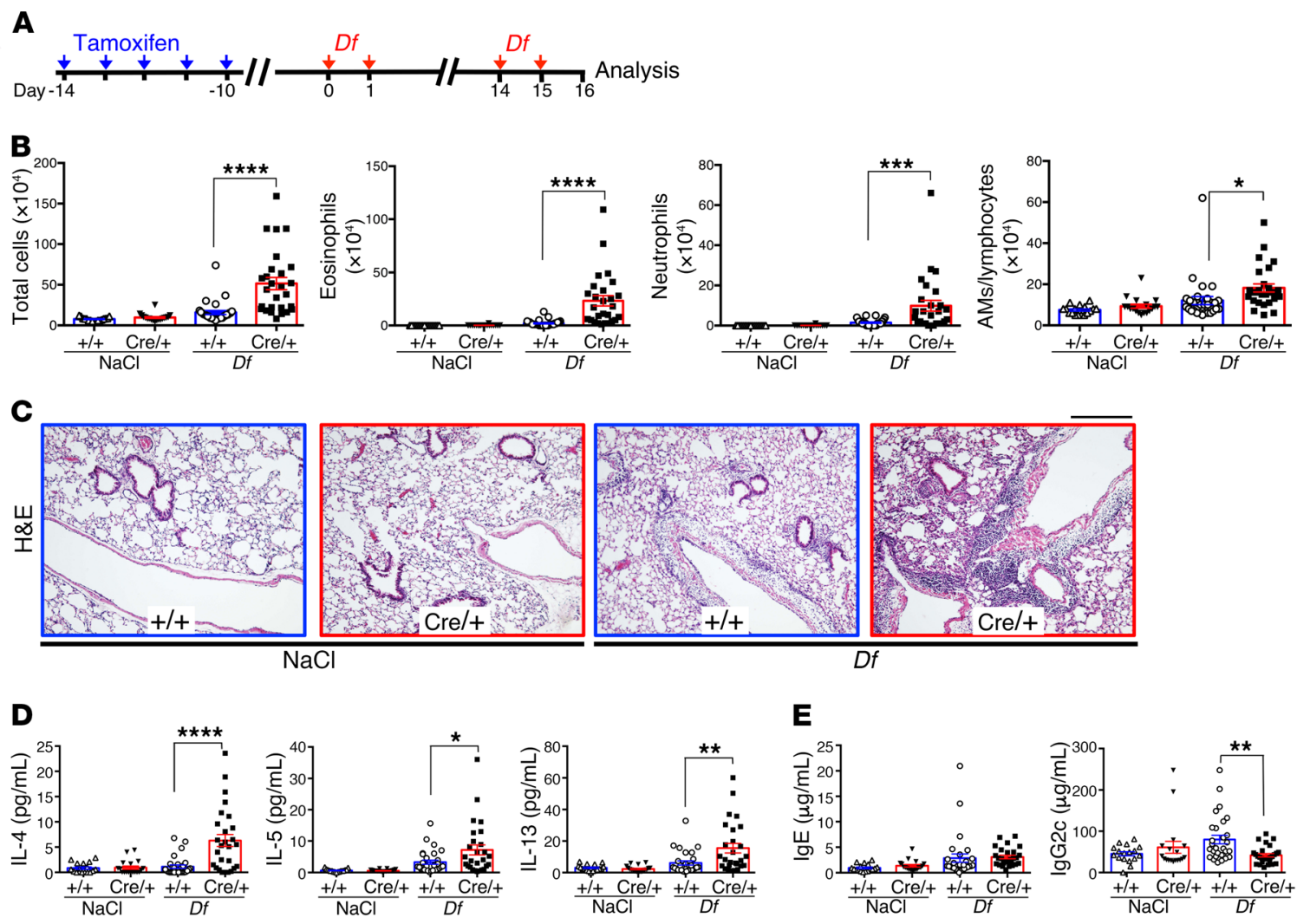

$\mathbf{E}$
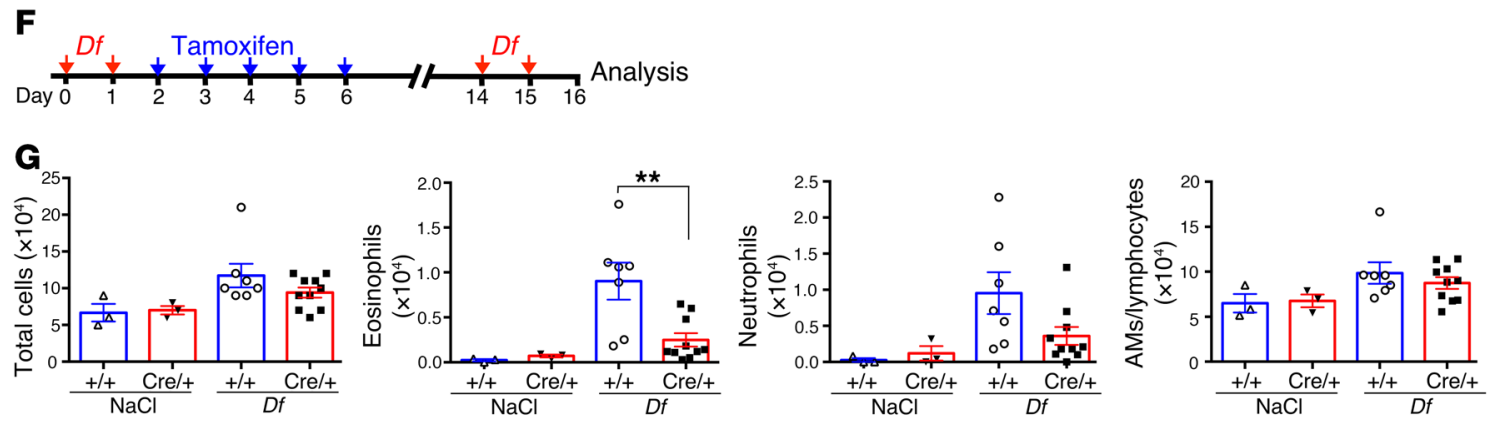

H
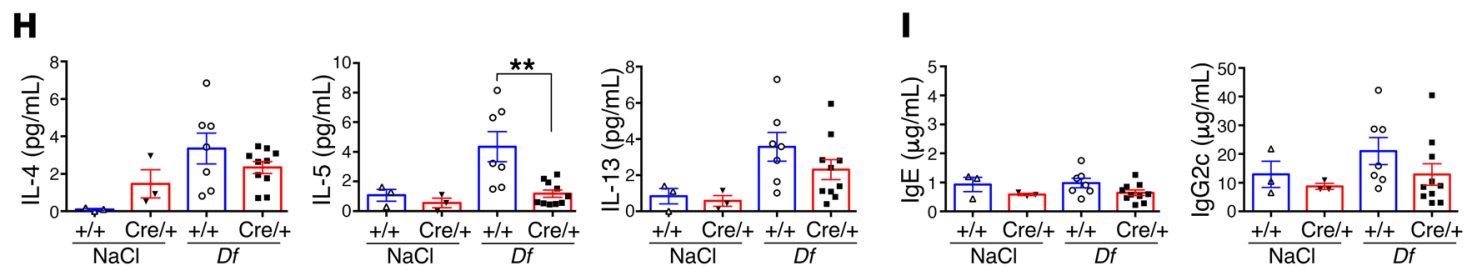

Figure 1. Deletion of $P 2 Y_{6}$ before, but not after, sensitization amplifies allergic lung inflammation induced by challenge with $D f$. (A) Protocol to induce allergic airway inflammation after deletion of $\mathrm{P}_{2} \mathrm{Y}_{6}$ by tamoxifen treatment. (B) Total/differential cell counts in BAL fluid of $\mathrm{NaCl}$ - or $D f$-treated $+/+$ (blue bars; $n=17, n=29$ ) and P2ry6 $6^{f / f / / / C r e /+}$ (Cre/+, red bars; $n=18, n=27$ ) mice on day 16. Data are from 5 experiments. (C) Representative lung tissue sections from $\mathrm{NaCl}$ - or $D f$-treated +/+ and P2ry6 fl/f//cre/+ mice stained with H\&E on day 16. Scale bar: $300 \mu \mathrm{m}$. (D and E) BAL fluid levels of IL-4, IL-5, and IL-13 (D) and total serum IgE and IgG2c (E) in NaCl- or Df-treated $+/+(n=17, n=29)$ and $P 2$ ryf $f^{f / f / / C r e /+}(n=18, n=27)$ mice on day 16. (F) Protocol used to induce allergic inflammation with deletion of P2Y after the sensitization phase. (C) BAL fluid cell counts of NaCl- or $D f$-treated $+/+(n=3, n=7)$ and $P 2 r y 6^{f / / f / /(r e /+}(n=3, n=$ 10) mice on day 16 when P2ry6 was deleted after the sensitization phase. (H and I) BAL fluid levels of IL-4, IL-5, and IL-13 (H) and total serum IgE and IgC2C (I) in $\mathrm{NaCl}$ - or $D f$-treated $+/+$ and $P 2 r y 6^{f / / f / / C r e /+}$ mice when $P 2 r y 6$ was deleted after the sensitization phase. Values are mean $\pm \mathrm{SEM}$. ${ }^{*} P<0.05,{ }^{* *} P<0.01,{ }^{* * *} P<$ $0.001,{ }^{* * *} P<0.0001$ vs. + / mice by 2 -way ANOVA followed by Tukey's multiple-comparisons test.

BAL fluids and higher levels of the corresponding transcripts in the $\mathrm{T}$ cell compartment $\left(\mathrm{CD} 3^{+} \mathrm{CD} 90^{+} \mathrm{CD} 45^{+}\right)$of the lungs. In contrast, there were no differences between strains in the cytokines generated by ILCs ( Lin $\left.^{-} \mathrm{CD} 9 \mathrm{O}^{+} \mathrm{CD} 45^{+}\right)$(Supplemental Figure 3, A-C).
To determine whether $\mathrm{P}_{2} \mathrm{Y}_{6}$ receptor signaling protected against T2I-mediated inflammation when P2ry6 deletion was restricted to the challenge phase, we delayed administration of tamoxifen to the mice to 24 hours after the second sensitiz- 
A P2ryG $G^{f / t / 1}$ Scgb1a1-Cre/+ mice
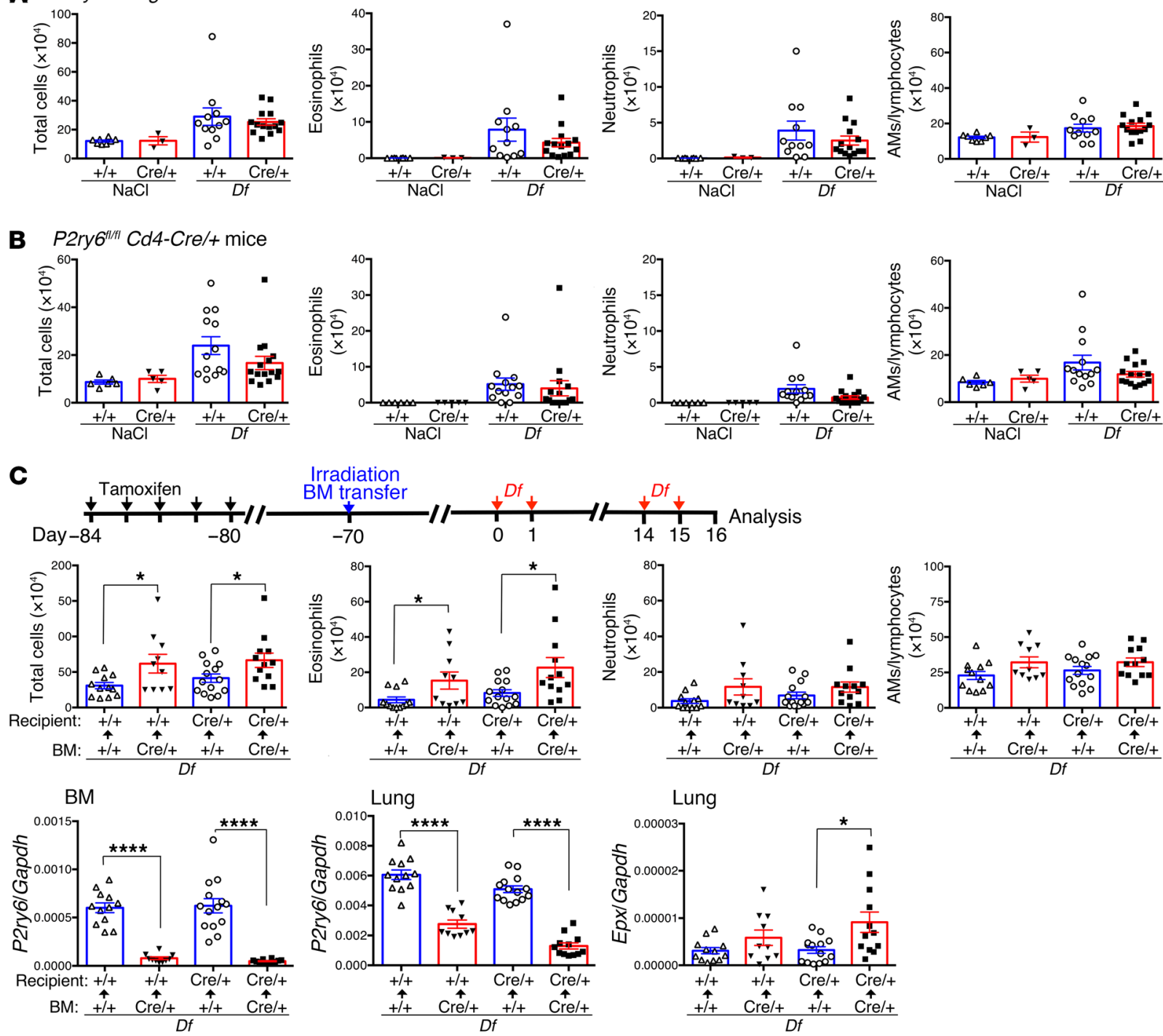

Figure 2. $\mathbf{P 2} \mathrm{Y}_{5}$ receptors on hematopoietic cells are involved in protection from $D$ f-induced allergic inflammation. (A) BAL fluid cell counts of $\mathrm{NaCl}$ - or $D f$-treated $+/+$ (blue bars; $n=8, n=11$ ) and P2ry $f^{f / / f l}$ Scgb1a1-Cre/+ (red bars; $n=3, n=14$ ) mice on day 16. (B) BAL fluid cell counts of $\mathrm{NaCl}$ - or $D f$-treated $+/+(n=6, n=13)$ and P2ry $f^{f l / f l} \mathrm{Cd} 4-\mathrm{Cre} /+(n=5, n=15)$ mice on day 16. (C) BAL fluid cell counts of chimeric mice. Lethally irradiated mice of the indicated genotypes received i.v. marrow from mice of the indicated genotypes (10-14 mice/group). P2ry6 transcripts in BM and lung tissue and Epx transcript in lung tissue from chimeric mice on day 16, as measured by qPCR. Data are expressed as ratio relative to Gapdh. Values are mean \pm SEM. All data are from 2 experiments. ${ }^{*} P<0.05,{ }^{* * *} P<0.0001 \mathrm{vs}$. indicated mice receiving $+/+$ BM by Mann-Whitney $U$ test, parametric $t$ test, or Welch's $t$ test (C).

ing dose of $D f($ Figure 1F). We verified deletion of P2ry6 in the lung and spleen by qPCR in this protocol (Supplemental Figure $4 \mathrm{~A})$. In marked contrast to the deletion of P2ry6 prior to sensitization, deletion after the sensitization significantly decreased $D f$-induced accumulation of eosinophils in BAL fluid (Figure 1G). Additionally, levels of IL-5 and quantities of Il4, Il5, Il13, and Il33 transcripts were significantly diminished in the BAL and lungs of $P 2 r y 6^{f / f / / C r /+}$ mice compared with $+/+$ controls after delayed tamoxifen administration (Figure $1 \mathrm{H}$ and Supplemental Figure $4 B)$. Total IgE, IgG2c, and IgM levels were similar in the 2 genotypes in this protocol and not significantly increased by $D f$ challenge (Figure 1I and Supplemental Figure 4C). Levels of mRNA encoding Cxcll and Il6 (each of which is generated by airway epithelial cells activated by $\mathrm{P}^{2} \mathrm{Y}_{6}$ signaling) (26) were significantly lower in the lungs of $P 2 r y 6^{f / f / / C r e /+}$ mice than $+/+$ controls when $P 2 r y 6$ deletion was restricted to the challenge phase (Supplemental Figure 5A). In contrast, these transcripts did not differ between strains when P2ry6 was deleted before sensitization (Supplemental Figure 5B). These data demonstrated that $\mathrm{P}_{2} \mathrm{Y}_{6}$ signaling during the allergen sensitization phase was critical for its ability to decrease T2Imediated inflammation at the challenge phase.

$P 2 Y_{6}$ expression by hematopoietic cells protects against $D f$-induced T2I. To identify specific cell types potentially responsible for the protective effect of $\mathrm{P}_{2} \mathrm{Y}_{6}$ receptor signaling during sensitization, we applied the sensitization and challenge protocol to 2 additional strains of conditional null mice: $P 2 r y 6^{A / A}$ Scgbla1-Cre/+ mice, in which deletion of $P 2 r y 6$ is driven by an epithelial (Clara) cell-specific 

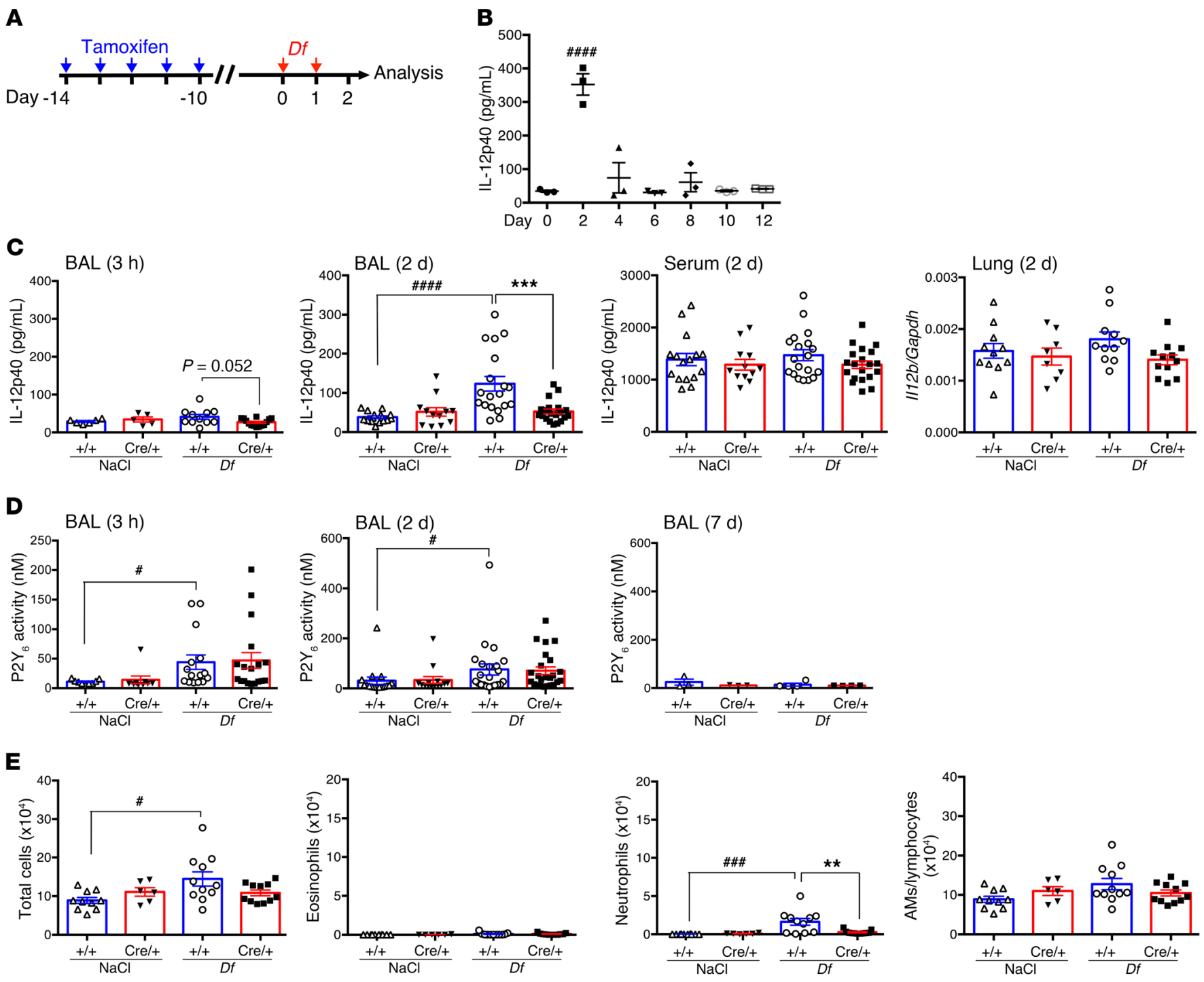

Figure 3. P2Y ${ }_{6}$ receptors regulate early alveolar IL-12 production. (A) Schematic of BAL and serum collection during the sensitization phase to assess levels of IL-12p40 and UDP and BAL fluid cell counts. (B) Time course of IL-12p40 production in BAL fluid from Df-treated WT mice $(n=3)$. (C) IL-12p40 production in BAL fluid and serum from NaCl- or $D f$-treated $+/+$ (blue bars) and $\mathrm{P} 2 \mathrm{ry} / \mathrm{f} / \mathrm{flf/ \textrm {cre } / +}$ (red bars) mice; and I/12b transcript in the lung of $\mathrm{NaCl}$ - or $\mathrm{Df}$-treated $+/+$ and P2ryf fl/f//cre/+ mice on day 2. (D) P2Y activity (UDP concentrations) on days 0 (3 hours), 2 , and 7 in BAL fluid was quantified by bioassay using $1321 \mathrm{~N} 1$ cells stably expressing mouse $\mathrm{P} \mathrm{Y}_{6}$. (E) BAL fluid cell counts of $\mathrm{NaCl}$ - or $D f$-treated $+/+$ and $P 2 r y f^{f / / f / / C r e /+}$ mice on day 2 . Values are mean $\pm \mathrm{SEM}$. Data are from at least 2 experiments, except for the time course experiment on IL-12p40 (B) and P2Y activity on day 7 (D, right panel). \#P<0.05, \#\#P<0.001 vs. $\mathrm{NaCl}$ treatment; ${ }^{\# \# \# P}<0.0001$ vs. day 0 (B) or NaCl treatment (C); ${ }^{* *} P<0.01$, ${ }^{* * *} P<0.001$ vs. + /+ mice; by 1-way (B) or 2-way (C and E) ANOVA followed by Tukey's multiple-comparisons test or nonparametric Kruskal-Wallis followed by Dunn's multiple-comparisons test (D).

promoter; and $\mathrm{P} 2 \mathrm{ry} 6^{\mathrm{G/fl}} \mathrm{Cd} 4-\mathrm{Cre} /+$ mice, in which $\mathrm{P} 2 \mathrm{ry} 6$ is deleted selectively on $\mathrm{T}$ cells at the double-positive thymocyte stage; along with respective control strains. Compared with the corresponding +/+ controls, neither conditional null strain showed significant differences in total BAL fluid cell counts or any specific cell subset (Figure 2, A and B). To determine whether hematopoietic or tissue-resident expression of $\mathrm{P}_{2} \mathrm{Y}_{6}$ mediated the protective effect of thereceptorduring sensitization, wetransferred BMfrom $P 2 r y 6^{A / f / / / C r e /+}$ mice into lethally irradiated $+/+$ controls and vice versa, and subjected the engrafted mice to the $D f$ sensitization and challenge protocol (Figure 2C). Both $+/+$ and P2ry $6^{\mathrm{ff} / \mathrm{/} / \mathrm{Cre} /+}$ recipients of BM from $P 2 r y 6^{A / f / / C r e /+}$ mice showed higher BAL fluid total cell and eosinophil counts than did recipients of +/+ BM (Figure 2C). qPCR analysis of the engrafted mice confirmed the repopulation of recipient BM with the donor genotype. Additionally, transferred BM accounted for approximately $80 \%$ of the P2ry6 transcripts in the lung of $D f$ sensitized and -challenged mice, indicating replenishment of $\mathrm{P}^{2} \mathrm{Y}_{6}$ receptors expressed by radiosensitive hematopoietic cell populations resident in the lung (Figure 2C). Epx transcript levels in the lungs of recipients of $P 2 r y 6^{\mathrm{A} / \mathrm{f} / \mathrm{Cr} / \mathrm{H}+\mathrm{+}}$ marrow were increased compared with those in recipients of +/+ BM (Figure 2C). We concluded from these experiments that the regulatory effect of $\mathrm{P}_{2} \mathrm{Y}_{6}$ signaling was mediated by a hematopoietic non-T cell.

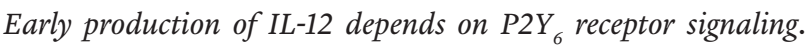
We next sought to further characterize the early $\mathrm{P}_{2} \mathrm{Y}_{6}$ receptordependent events responsible for the dampened type 2 immune 


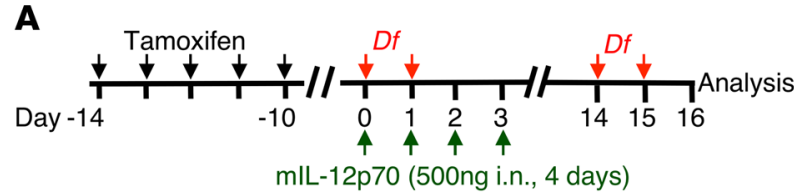

B
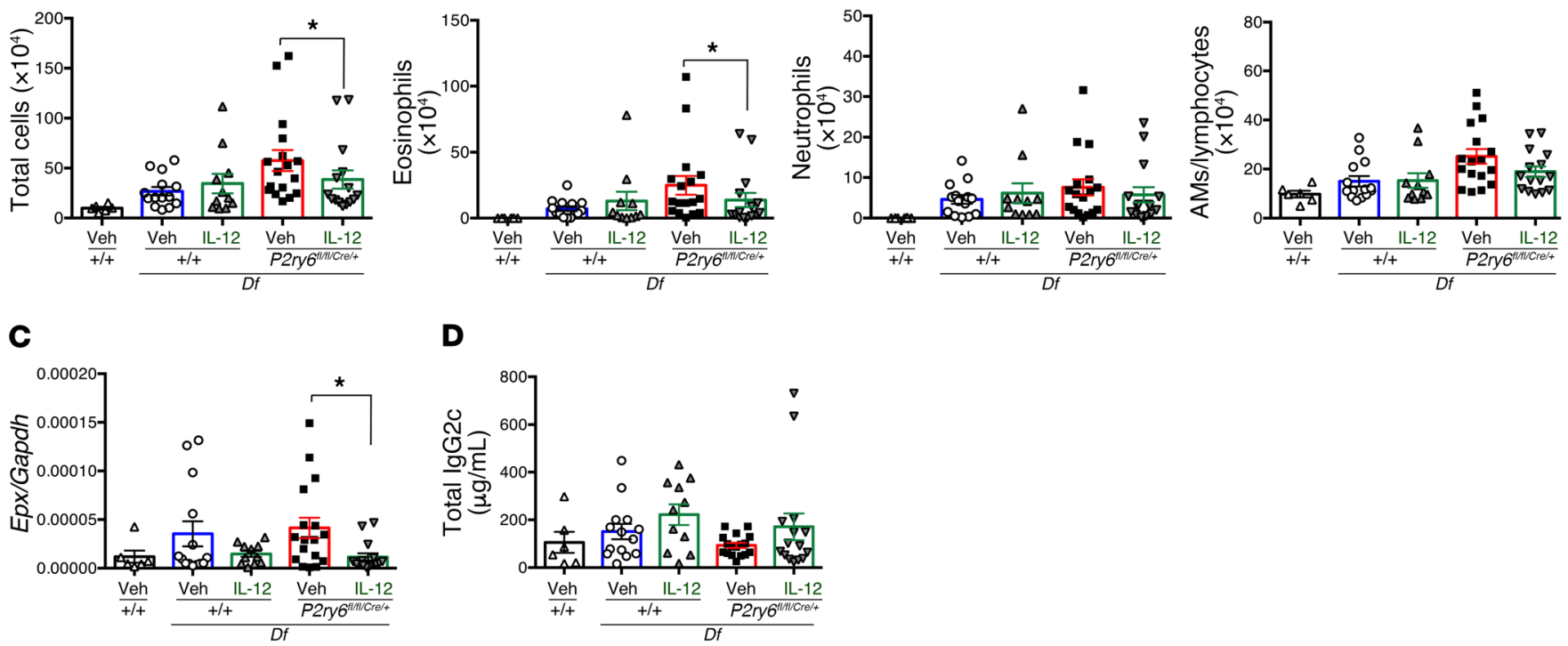

Figure 4. Restoration of IL-12 reverses eosinophilic lung inflammation in P2ry6 fl/f//cre/+ mice. (A) Intranasal administration of IL-12p70 (500 ng) for 4 days on early stages prevents enhanced eosinophilic lung inflammation in P2ry $6^{f / f / / / \text { re/ } /+}$ mice. IL-12p40 levels in BAL fluid from i.n. $D f$-sensitized or IL-12p70-treated WT mice on day 2: vehicle, $44 \pm 6 \mathrm{pg} / \mathrm{mL} ; D f: 217 \pm 2 \mathrm{~mL}$; IL-12p70: $248 \pm 3 \mathrm{pg} / \mathrm{mL}(n=4)$. (B) BAL fluid cell counts of $D f$-treated $+/+$ and

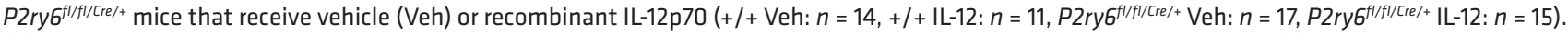
(C) Epx transcript in the lung tissue of $D f$-treated $+/+$ and P2ry $6^{f / / f / / C r e /+}$ mice that received vehicle or recombinant IL-12p70. (D) Total serum IgG2c from $D f$-treated $+/+$ and $P 2 r_{y} G^{f / f / / / C r e /+}$ mice that received vehicle or recombinant IL-12p70. Values are mean \pm SEM. Data are from 3 experiments. ${ }^{*} P<0.05$ vs. vehicle by Mann-Whitney $U$ test.

responses during sensitization. We examined BAL fluid from $P 2 r y 6^{f / f l / C r e /+}$ mice and $+/+$ controls for the presence of cytokines produced by resident hematopoietic cells during innate immune responses that regulate subsequent adaptive responses after administration of tamoxifen and a sensitizing dose of $D f$ (Figure 3A). We measured IL-12p40, a subunit of both the Th1-promoting factor IL-12 and the Th17-promoting factor IL-23, during the sensitization phase. We also examined the BAL fluid for IL-23 (using an ELISA with an IL-12p19 capture antibody and an IL-12p40 detection antibody); IL-18, which can facilitate type 1 cytokine production (34); and IL-10, which is immunoregulatory. IL-12p40 levels in the BAL fluid tended to increase as early as 3 hours after the first sensitizing dose of $D f$ in $+/+$ but not $P 2 r y 6^{f / f l / C r e /+}$ mice, reaching a peak on day 2 (16 hours after the second sensitizing dose) and declining thereafter (Figure 3, B and C). Such an increase in BAL fluid IL-12p40 levels did not occur in $P 2 r y 6^{f / f / / C r e /+}$ mice (Figure 3C). Serum levels of IL-12p40 were equivalent in the 2 strains and not altered by sensitization to $D f$ (Figure 3C), and whole-lung $I l 12 b$ transcripts were modestly reduced in the $P 2 r y 6^{f / f / / C r /+}$ mice relative to +/+ controls. IL-12p70, IL-23, and IL-10 levels were below the limit of detection in the BAL fluid (data not shown). IL-12p70 levels in lung homogenates were similarly low in $D f$ - and NaCl-treated mice, and did not differ between strains (Supplemental Figure 6A). $D f$ treatment induced modest and equivalent increases in BAL fluid levels of IL-18 in both strains on day 2, without significant changes in serum IL-18 levels or Il18 mRNA expression in the lungs (Supplemental Figure 6B).

To quantify the levels of extracellular UDP in the alveolar space, we developed a $\mathrm{P}_{2} \mathrm{Y}_{6}$ receptor-dependent calcium flux bioassay in stably transfected mouse $\mathrm{P}_{2} \mathrm{Y}_{6}$-expressing 1321N1 cells capable of detecting UDP in BAL fluid at levels as low as $0.2 \mathrm{nM}$. Both UDP and BAL fluid induced calcium fluxes in $\mathrm{P}_{2} \mathrm{Y}_{6}$-transfected cells, but not parental $1321 \mathrm{~N} 1$ cells, that were prevented by treatment with apyrase (Supplemental Figure 7, A-C). Among the 4 nucleotides, UTP and ADP showed more than 30 and 300 times lower affinity, respectively, to mouse P2Y than UDP (Supplemental Figure 7D). In mice of both genotypes, the first sensitizing dose of $D f$ increased UDP activity in BAL fluid collected compared with the $\mathrm{NaCl}$-challenged controls as early as 3 hours (Figure 3D). These increases persisted on day 2, then declined by day 7 to basal levels (Figure 3D). BAL fluid UDP levels in the $D f$-treated $P 2 r y 6^{f l / f / / C r e /+}$ mice were indistinguishable from those in $+/+$ controls at 3 hours and day 2 , but were higher in the $P 2 r y 6^{f / f / / C r e /+}$ mice on day 16 in both the before-sensitization and delayed-tamoxifen protocols (Supplemental Figure 7E). Total cell counts and neutrophils in the BAL fluid on day 2 increased in $+/+$ but not $P 2 r y 6^{f / f / / C r /+}$ mice (Figure $3 \mathrm{E}$ ). We concluded from these experiments that the release of IL-12p40 during the sensitization 
A

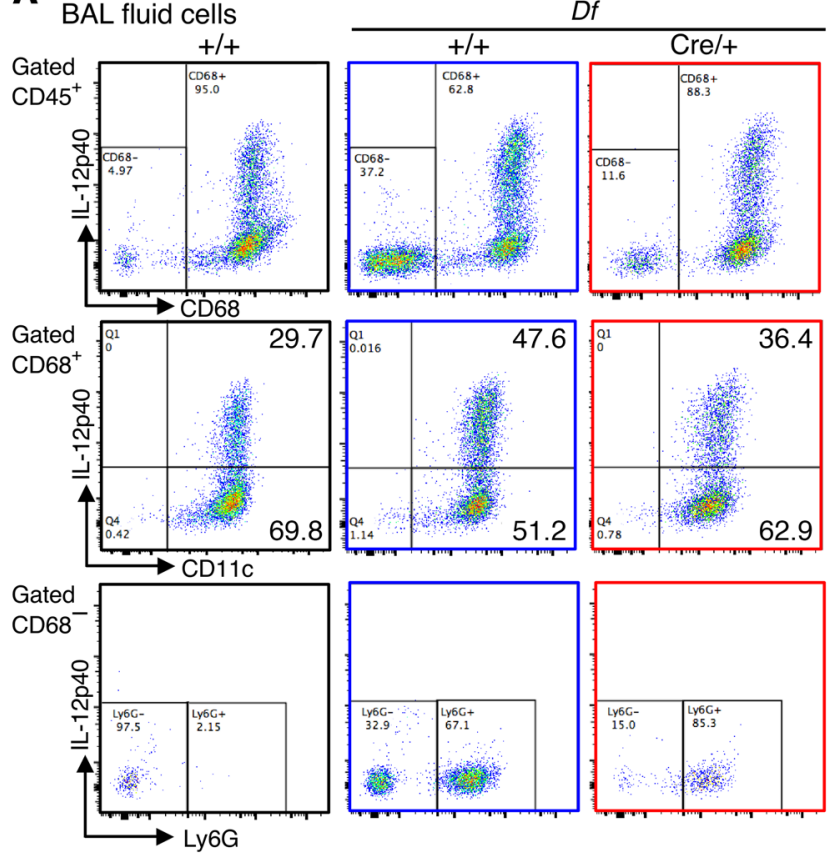

(Gated CD68+) IL-12p40 hi $^{\text {hi }} 11 \mathrm{C}^{+}$

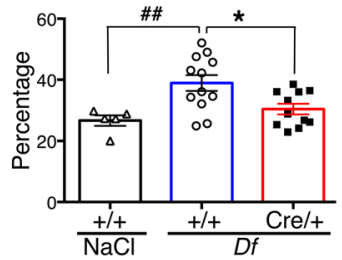

(Gated CD68 ${ }^{+}$) IL-12p40 ${ }^{\text {lo }} \mathrm{CD} 11 \mathrm{C}^{+}$

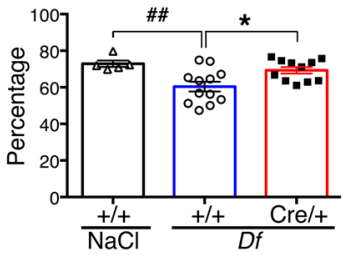

Ly6G- cells

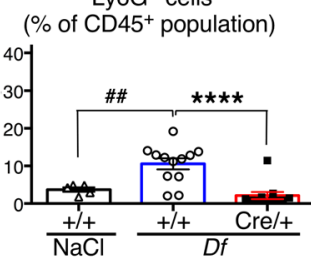

Ly6G $^{+}$cells

(\% of CD $45^{+}$population)

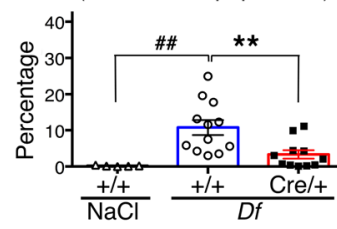

B

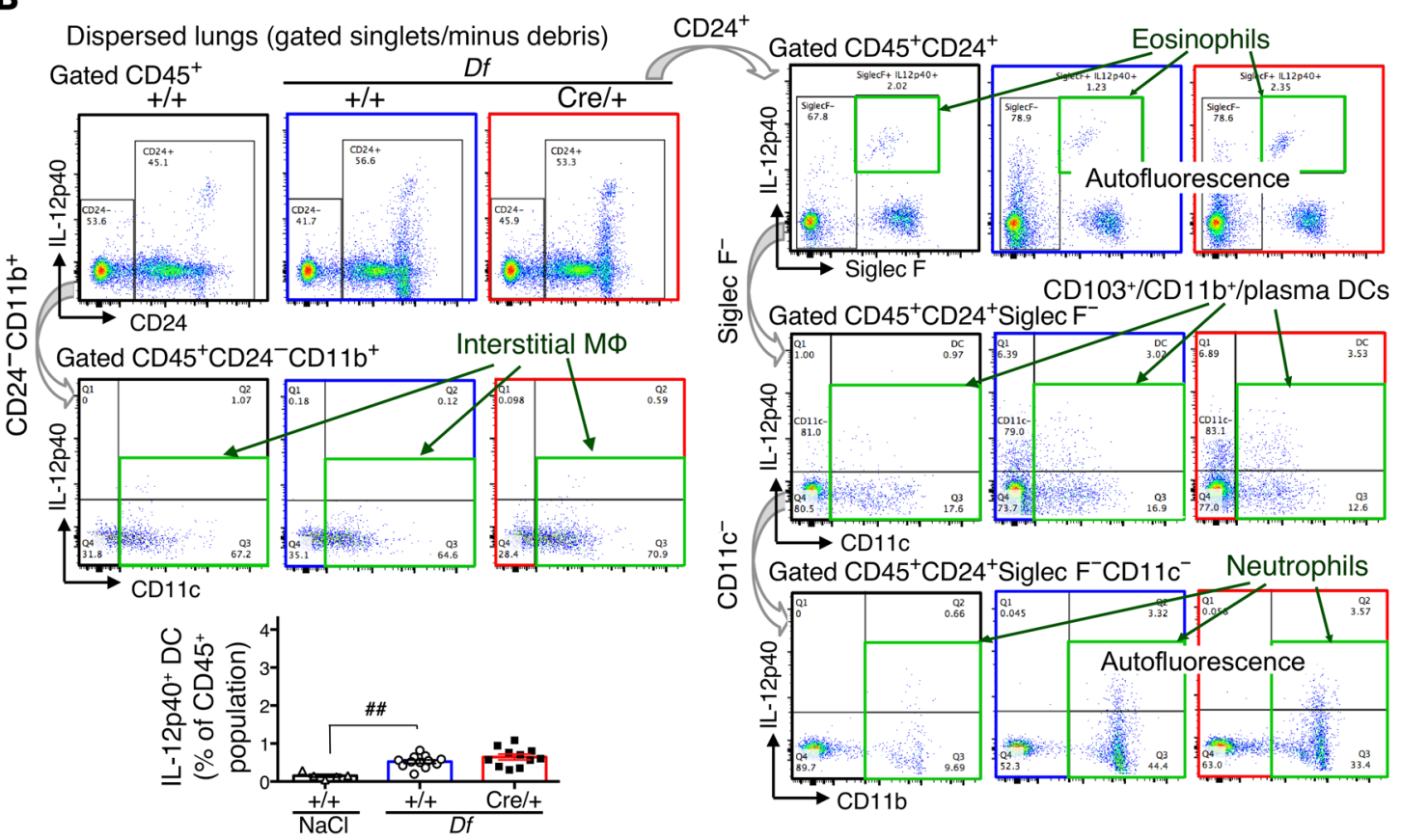

Figure 5. AMs are the predominant sources of $\mathbf{P 2 Y}_{\mathbf{6}}$-regulated IL-12p40. (A) BAL fluid cells obtained 4 hours after the second dose of NaCl (left) or $D f$ $\left(+/+\right.$ and $\left.P 2 r y 6^{f f / f / / C r e /+}\right)$. Staining of the CD45+ gate for CD68 and intracellular IL-12p40 is shown in the top row. Surface CD11c staining of CD45+CD68 ${ }^{+}$cells and surface Ly6C staining of CD45+CD68- cells are displayed in the middle and bottom rows, respectively. Quantifications are shown in the bar graphs $(+/+$ Veh: $n=5,+/+D f: n=12$, and P2ryffl/f//Cre/+ $D f: n=11)$. (B) Cells were isolated from digested lungs. Analysis of IL-12p40 in interstitial macrophages

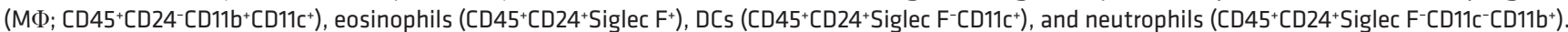
The IL-12p40+ DC population is shown in the bar graph $\left(+/+\right.$ Veh: $n=5,+/+D f: n=12$, and $P 2$ ry $\left.6^{f / / f / / \text { re } /+} D f: n=11\right)$. Values are mean \pm SEM. \#\# $P<0.01$ vs. $\mathrm{NaCl}$-treated mice; ${ }^{*} P<0.05,{ }^{* *} P<0.01,{ }^{* * *} P<0.0001 \mathrm{vs} .+/+$ mice by 1 -way ANOVA followed by Tukey's multiple-comparisons test.

phase coincided with the release of UDP, as well as a small influx of neutrophils, and that IL-12p40 release and neutrophil influx

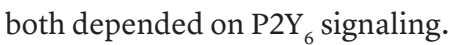

To determine whether the $\mathrm{P}_{2} \mathrm{Y}_{6}$ receptor-dependent differences in BAL fluid IL-12p40 levels persisted at the challenge phase, we measured IL-12p40 levels in samples from $\mathrm{NaCl}$ - and $D f$-challenged mice on day 16 . Compared with $\mathrm{NaCl}$-challenged controls, BAL fluid from $D f$-challenged mice showed markedly increased levels of IL-12p40, but with no significant differences between strains (Supplemental Figure 8). Thus, P2Y $_{6}$ receptor 
$\mathbf{A}$

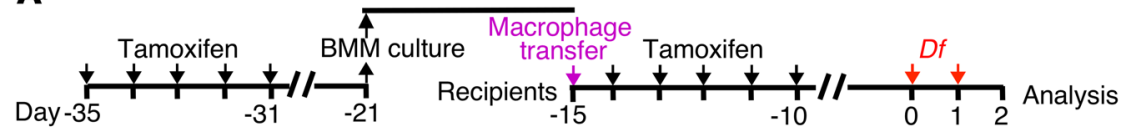

B

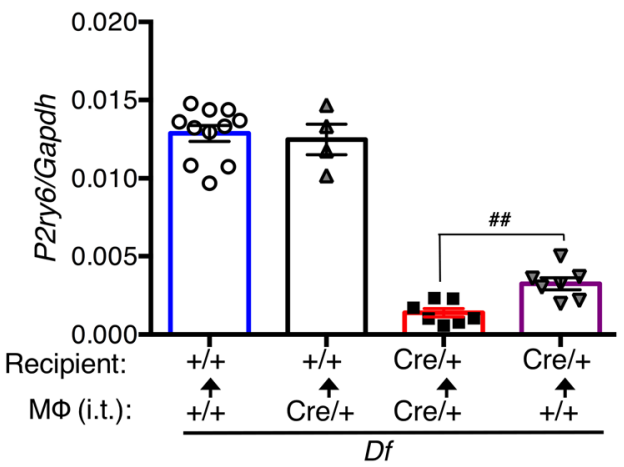

C

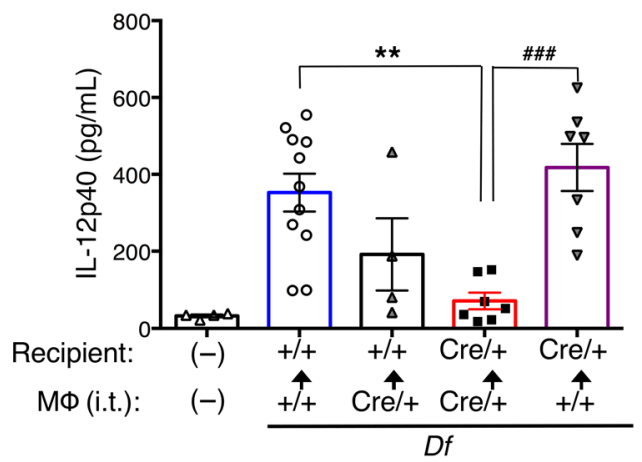

D

BAL $\quad(-) \quad D f(2 \mathrm{~d})$

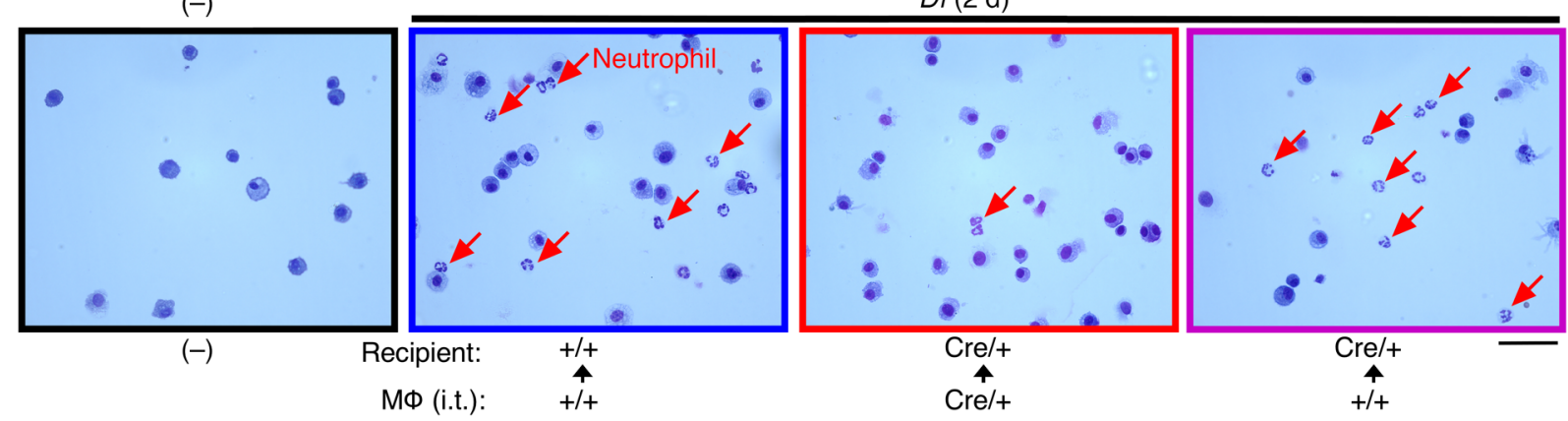

E

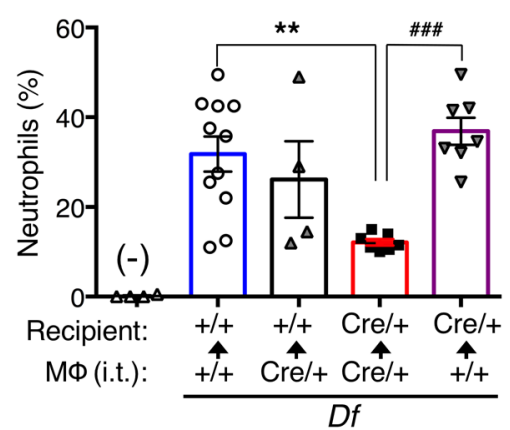

F

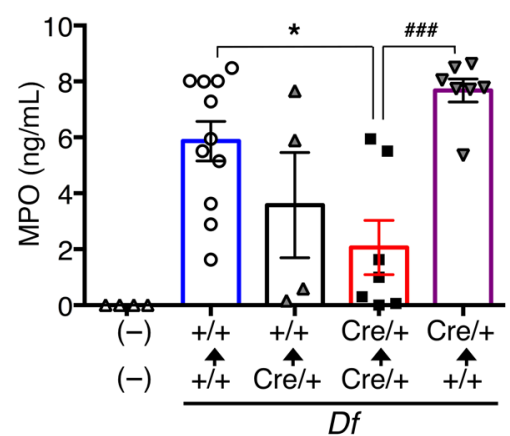

G

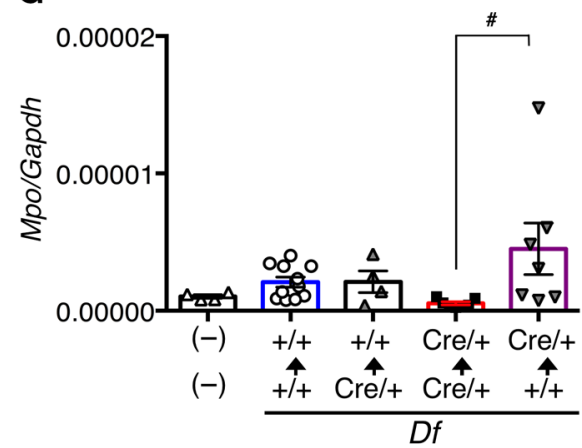

Figure 6. Pulmonary +/+ macrophage transplantation restores $D f$-induced IL-12p40 production and neutrophil infiltration during sensitization of P2ry6 fl/f//cre/+ mice. (A) BM macrophages from +/+ or P2ry6 fl/f//Cre/+ mice were administered (i.t.) into +/+ and P2ry6 f//f//cre/+ mice: +/+ macrophages into +/+

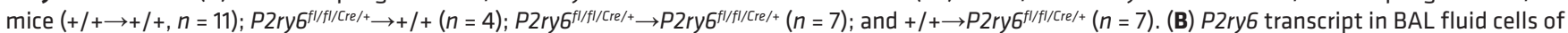
pulmonary macrophage transplantation-treated (PMT-treated) $+/+$ and $P 2 r y 6^{f / / f / / r e /+}$ mice on day 2 (17 days after transplantation). \#\# $P<0.01$ by parametric $t$ test. (C) BAL fluid IL-12p40 from PMT-treated $+/+$ and P2ry6 f/f//cre/+ mice on day 2. (D) Diff-Quick-stained BAL fluid cells from the indicated mice. Red arrows indicate neutrophils. Scale bar: $50 \mu \mathrm{m}$. (E) Percentages of neutrophils in BAL fluid from PMT-treated +/+ and P2ry $6^{f / / f / / \text { re } /+}$ mice. (F) MPO levels in BAL fluid of PMT-treated $+/+$ and $P 2 r y 6^{f l / f / / C r e /+}$ mice on day 2. (C) BAL cell Mpo transcript levels of PMT-treated mice on day 2 . Values are mean \pm SEM. Data

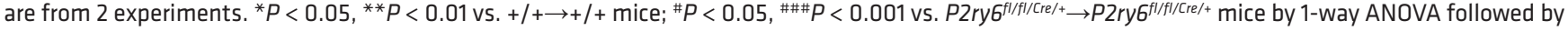
Tukey's multiple-comparisons test (C-C).

signaling was essential for the early production of IL-12p40 but not for its production after sensitization and when airway inflammation was established.

We next asked whether IL-12 production at the sensitization phase conveyed the protective effect of $\mathrm{P}_{2} \mathrm{Y}_{6}$ receptor signaling at the challenge phase. To test this hypothesis, we administered exogenous recombinant IL-12p70 (500 ng/mouse) i.n. to both +/+ and P2ry $6^{A / f / C r e /+}$ mice on 4 successive days beginning on the first day of the sensitization phase (Figure 4A). IL-12p40 levels in BAL fluid from the IL-12p70-treated WT mice $(248 \pm 31 \mathrm{pg} / \mathrm{mL})$ were 
A

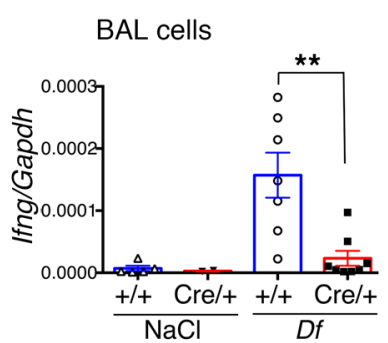

B

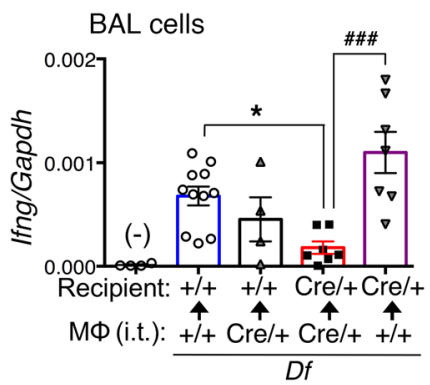

C

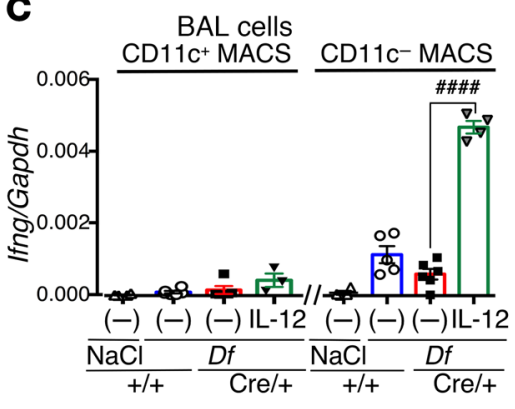

D
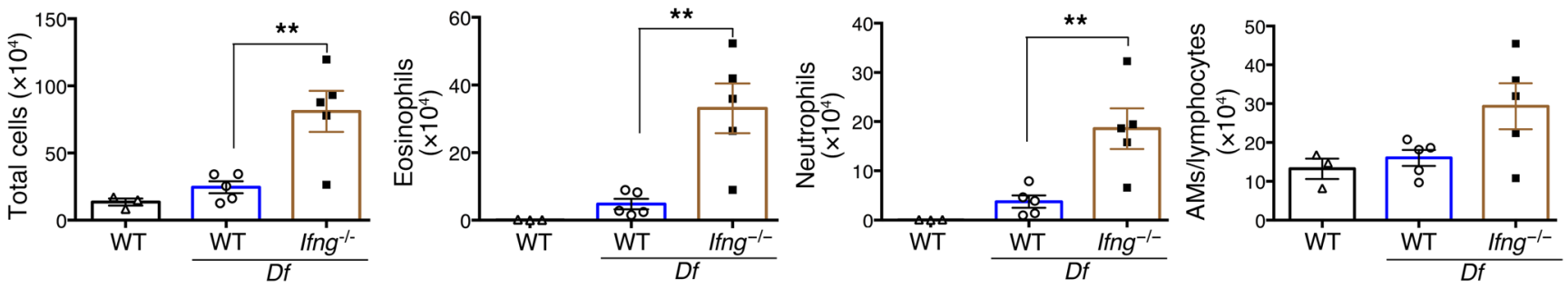

E
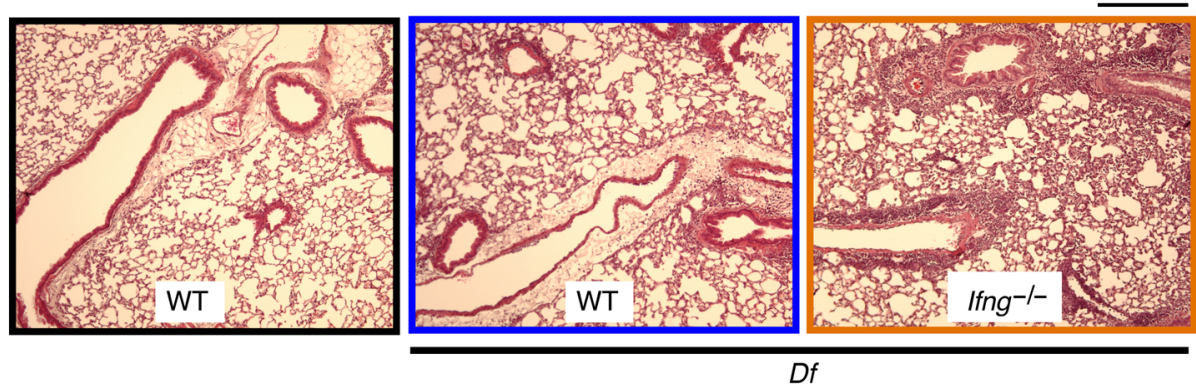

$\mathbf{F}$

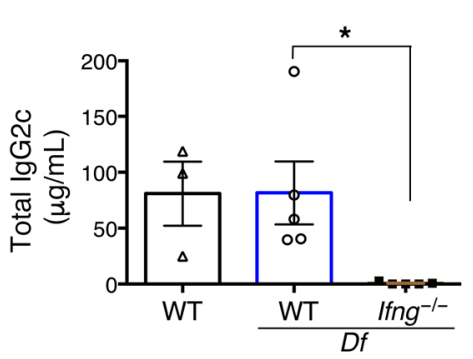

G
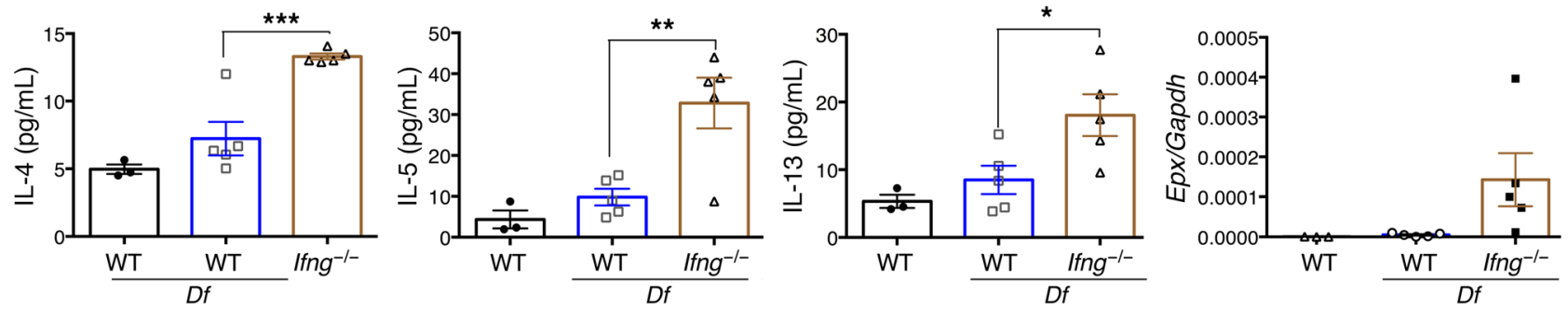

Figure 7. P2 $\mathrm{Y}_{5}$-dependent IL-12 from AMs induces a protective IFN- $\gamma$ signature. (A) Ifng transcripts in BAL fluid cells and lungs from NaCl- or $D f$-treated $+/+$ and $P 2 r y 6^{f / / f / /(r e /+}$ mice on day $2 .{ }^{* *} P<0.01$ vs. $+/+$ mice. (B) Ifng transcripts in BAL fluid cells from mice engrafted with $+/+$ or $P 2$ ry $6^{f / / f / /(r e /+}$ macrophages

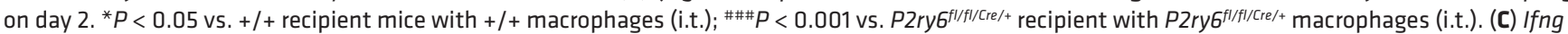

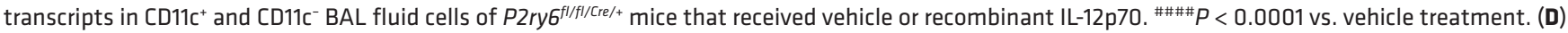
BAL fluid cell counts of $D f$-treated WT and $I f g^{-1-}$ mice on day 16. (E) Representative lung sections from $D f$-treated WT and $I f n g^{-1-}$ mice were stained with H\&E on day 16. Scale bar: $300 \mu \mathrm{m}$. (F) Total serum IgC2c of $D$ f-treated WT and Ifng ${ }^{-1-}$ mice quantified on day 16. (C) Levels of IL-4, IL-5, IL-13, and of Epx transcript in BAL fluid cells of $\mathrm{NaCl}$ - or $D f$-treated WT and Ifng ${ }^{-1-}$ mice. Values are mean $\pm \mathrm{SEM}$. ${ }^{*} P<0.05,{ }^{* *} P<0.01,{ }^{* *} P<0.001 \mathrm{vs}$. WT mice by 1 -way (B-G) or 2-way (A) ANOVA followed by Tukey's multiple-comparisons test.

similar to those detected in $D f$-sensitized WT mice $(217 \pm 23 \mathrm{pg} /$ $\mathrm{mL}$ ) (Figure 4A). On day 16, IL-12p70-treated P2ry $6^{\mathrm{A} / \mathrm{f} / \mathrm{Cr} / \mathrm{t} / \mathrm{p} \text { mice }}$ showed decreased BAL fluid total cell and eosinophil, but not neutrophil, numbers compared with sensitized and challenged $P 2 r y 6^{A / f / / / \mathrm{Cr} / \mathrm{H}}$ mice that did not receive IL-12p70 (Figure 4B). Exogenous IL-12p70 did not alter total or differential BAL fluid cell counts in $D$-challenged + /+ mice compared with control mice not receiving IL-12p70. Epx transcript levels in the lungs of IL-12p70-treated
$D f$-challenged $P 2 r y 6^{A f / / / C r e /+}$ mice were sharply reduced compared with those of their counterparts that did not receive IL-12p70 (Figure 4C). Furthermore, IL-12p70 administration tended to increase serum levels of IgG2c in the $D f$-challenged $P 2 r y 6^{f / f / / \mathrm{Cre} /+}$ mice to levels comparable to those observed in $+/+$ controls (Figure 4D). From these experiments, we concluded that IL-12 generated at sensitization was necessary for $\mathrm{P}_{2} \mathrm{Y}_{6}$ receptor-dependent control of type 2 immunopathology and $\operatorname{IgG} 2 \mathrm{c}$ production at challenge. 
A
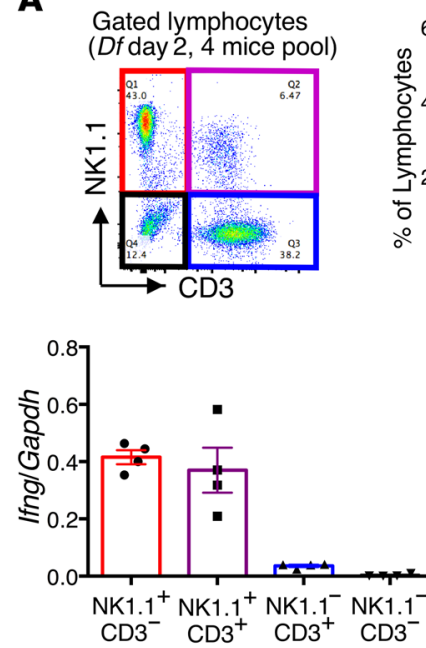

D

Gated lymphocytes/CD45 + /live cells
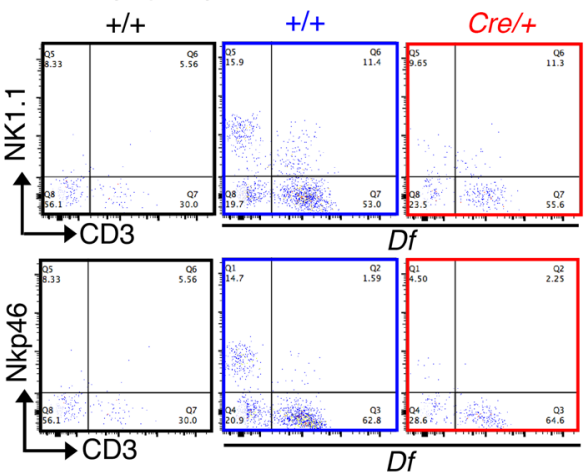

E
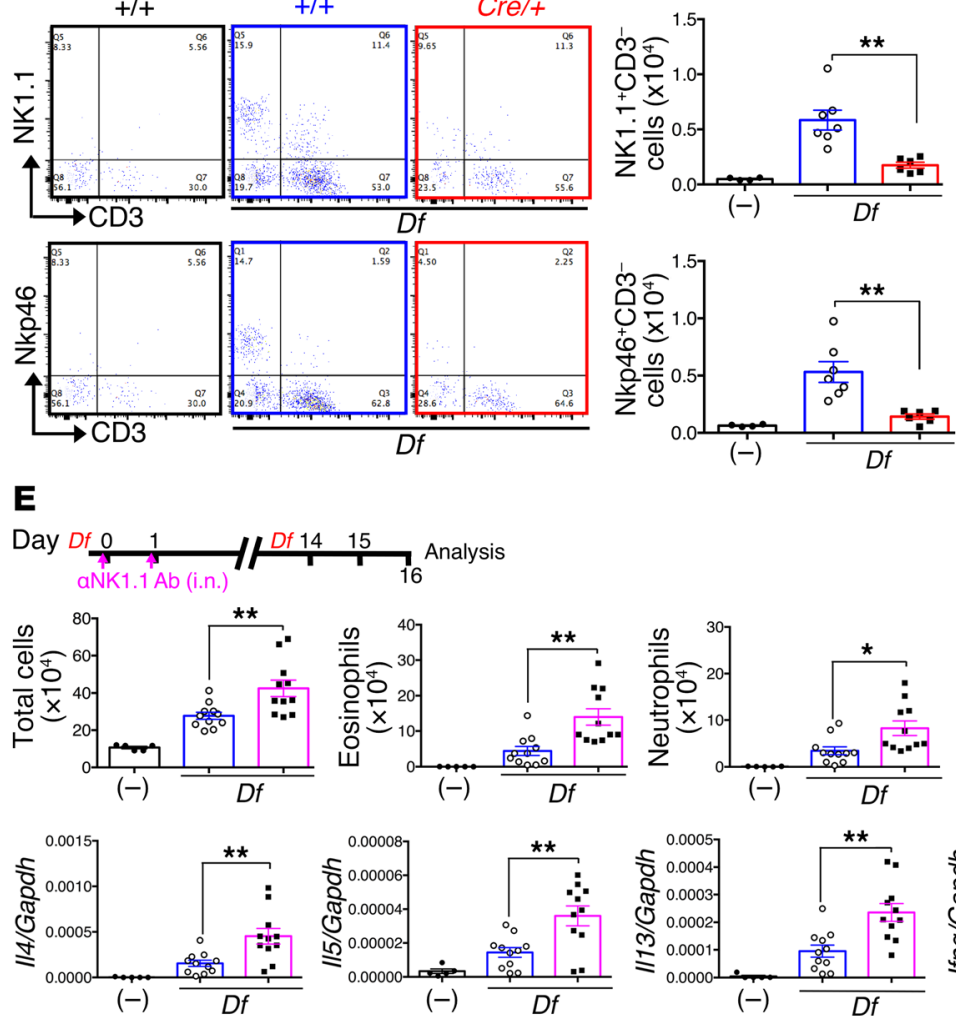

$(-)$
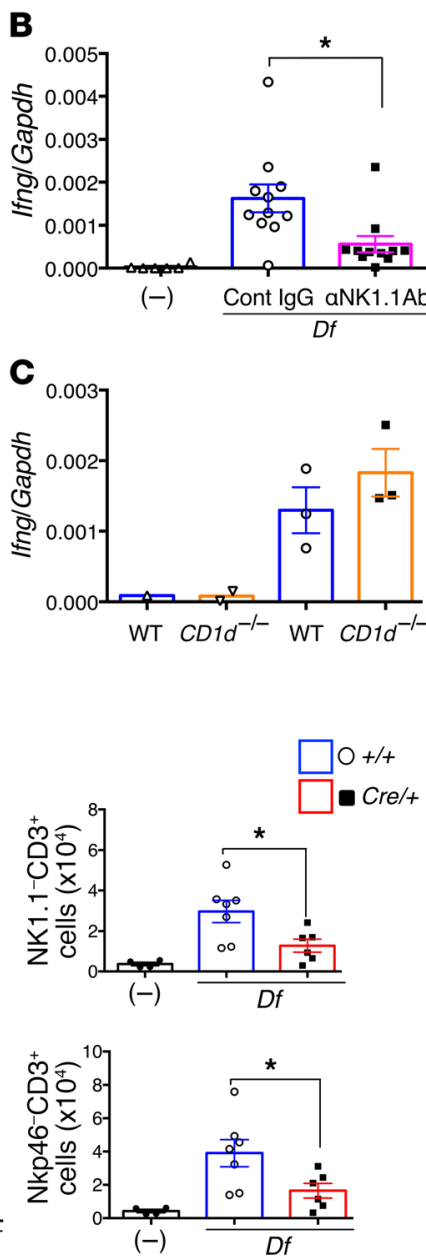

Figure 8. P2Y ${ }_{6}$ regulates the influx of protective IFN- $\gamma$-producing NK cells. (A) Characterization of BAL fluid lymphocytes from $D f$-treated WT mice on day 2 (4 mice per pool). Top row: Percentages of the indicated subgroups. Bottom row: Ifng transcripts relative to Gapdh in each population after the cell sorting. Data are expressed as arbitrary units (Ifng/Gapdh $\times$ numbers of cells) ( $n=4$; bottom row). Data are from 2 experiments. (B) Effect of i.n. anti-NK1.1 $\mathrm{Ab}$ (days $\mathrm{O}$ and 1 ) on expression of Ifng transcripts by BAL fluid cells of $D f$-treated WT mice. (C) Ifng expression by the BAL fluid cells from WT and $C d 1 d^{-/-}$ mice on day 2. (D) Lymphocyte subsets in BAL fluid obtained from $D f$-treated $+/+$ and $P 2$ ry $6^{f / f / / / \text { re } /+}$ mice after the second dose of $D f$. Representative plots are shown and quantitated in the bar graphs (+/+: $n=4 ;+/+D f: n=7$; and $\left.P 2 r y 6^{f / / f / / r e /+} D f: n=6\right)$. (E) Effect of anti-NK1.1 Ab treatment at sensitization (days 0 and 1 ) on BAL fluid cell counts on day 16 . Data are from 3 experiments. Values are mean \pm SEM. ${ }^{*} P<0.05,{ }^{*} P<0.01$ by 1 -way ANOVA followed by Tukey's multiple-comparisons test.

AMs are the dominant source of $P 2 Y_{6}-$ regulated $I L-12$. To identify the cellular source(s) of UDP/P2Y 6 receptor-dependent IL-12p40 production, we analyzed cells from both BAL fluid and enzymatically dispersed lungs for intracellular IL-12p40 protein by flow cytometry. Samples were collected from $+/+$ and
$P 2 r y 6^{f / f / / / C r e /+}$ mice before and 4 and 8 hours after the first and second sensitizations with $D f$. The cells were permeabilized and stained with mAbs against specific lineage markers and IL-12p40, respectively. Before sensitization, approximately $95 \%$ of BAL fluid cells in both $+/+$ and $P 2 r y 6^{A / f / / / r e /+}$ mice were $\mathrm{CD} 68^{+}$macro- 
A
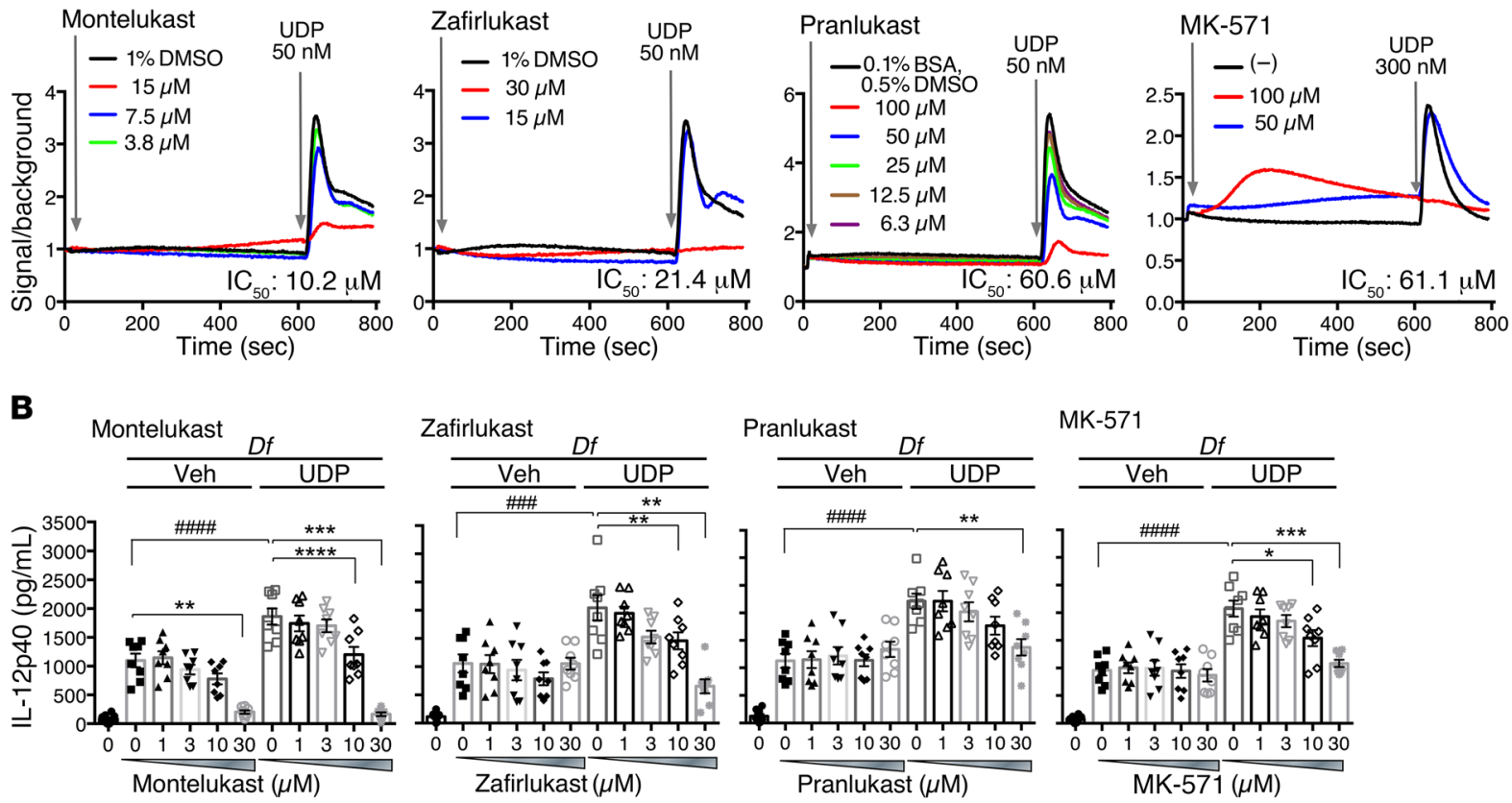

C
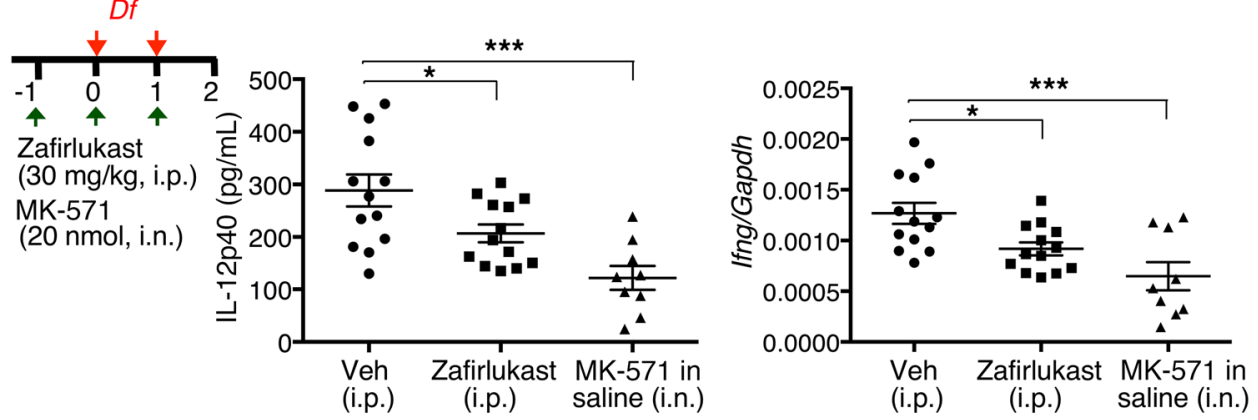

Correlation of IL-12p40 and lfng

D
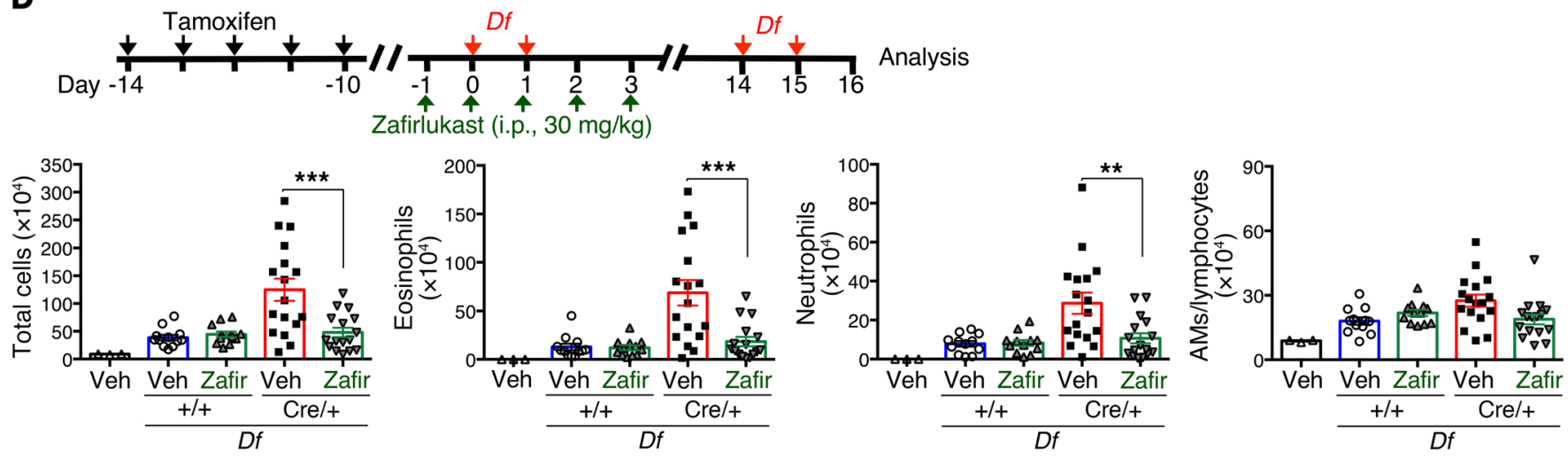

Figure 9. CysLT $R$ antagonists inhibit early $P_{2} Y_{6}$ receptor-dependent signaling that counterbalances $C_{y s L T} R$-induced $T_{2}$ I priming function. (A) CysLT $R$ antagonists blocked UDP-elicited calcium flux induced in 1321N1 cells stably expressing mouse P2ry6 (montelukast, zafirlukast, and pranlukast) and the macrophage cell line RAW 264.7 (MK-571). Values are mean $(n=4)$. (B) The CysLT, R antagonists all inhibited the UDP-elicited (10 $\mu$ M) potentiation of $D f$ induced IL-12p40 generation in BM-derived macrophages $(n=8)$. (C) Effect of zafirlukast (i.p.) or MK-571 (i.n.) at sensitization on the BAL concentration of IL-12p40 and expression of Ifng transcripts by BAL fluid cells. The correlation between BAL concentration of IL-12p40 and Ifng transcripts is shown. (D) BAL fluid cell counts of $\mathrm{NaCl}$ - or $D f$-treated $+/+$ and $P 2 r y f^{f / / f / / C r e /+}$ mice administered zafirlukast (i.p.) at sensitization $(+/+$ Veh: $n=12 ;+/+$ zafirlukast: $n=$ 12; P2ry6 f/ff//Cre/+ Veh: $n=17$; and P2ry6 f//f//Cre/+ zafirlukast: $n=16)$. \#\#\# $P<0.001$, \#\#\#\# $P<0.0001,{ }^{*} P<0.05,{ }^{* *} P<0.01,{ }^{* * *} P<0.001$, ${ }^{* * * *} P<0.0001$ by 1 -way ANOVA followed by Tukey's multiple-comparisons test. Values are mean \pm SEM. Data are from 2 experiments, except for the calcium flux experiments. 
phages, of which approximately $30 \%$ expressed IL-12p40 (Figure $5 \mathrm{~A})$. The percentages of $\mathrm{CD} 68^{+}$macrophages expressing IL-12p40 in $+/+$ mice increased by approximately $60 \%$ by 4 hours after the second sensitizing dose of $D f$ and remained higher than in $\mathrm{NaCl}$ treated controls to day 2 ( 24 hours after the second sensitizing dose) (Supplemental Figure 9A and Figure 5A), while the percentages of IL-12p $40^{\text {lo/neg }} \mathrm{CD} 68^{+}$cells decreased. The percentage of $\mathrm{CD} 8^{+}$cells expressing IL- $12 \mathrm{p} 40^{+}$did not increase significantly in $P 2 r y 6^{f / f / / C r e /+}$ mice in response to $D f$ (Figure 5A, top row). All of the IL-12p $40^{+} \mathrm{CD} 68^{+}$cells expressed CD11c (Figure 5A, middle row), consistent with their identity as AMs. At 4 hours after the second sensitizing dose, $D f$ caused an influx of Ly $6 \mathrm{G}^{+}$neutrophils and Ly6G- lymphocyte-sized cells into the BAL fluid of +/+ but not $P 2 r y 6^{f / f / / \mathrm{Cre} /+}$ mice, both of which were negative for IL-12p40 (Figure 5A, bottom row). Single-cell suspensions of dispersed lungs contained interstitial macrophages $\left(\mathrm{CD} 45^{+} \mathrm{CD} 24^{-} \mathrm{CD} 11 \mathrm{~b}^{+}\right.$ $\mathrm{CD} 11 \mathrm{c}^{+}$) that were IL-12p40 negative (Figure 5B). The eosinophils $\left(\mathrm{CD} 45^{+} \mathrm{CD} 24^{+}\right.$Siglec $\left.\mathrm{F}^{+}\right)$and neutrophils $\left(\mathrm{CD} 45^{+} \mathrm{CD} 24^{+}\right.$Siglec $\mathrm{F}^{-} \mathrm{CD} 11 \mathrm{c}^{-} \mathrm{CD} 11 \mathrm{~b}^{+}$) present in small numbers in the lungs after $\mathrm{Df}$ sensitization were autofluorescent, and the IL-12p40-positive plasmacytoid DCs $\left(\mathrm{CD} 45^{+} \mathrm{CD} 24^{+}\right.$Siglec $\left.\mathrm{F}^{-} \mathrm{CD} 11 \mathrm{c}^{+}\right)$did not differ between $+/+$ and $P 2 r y 6^{f / / f / / C r /+}$ mice (Figure 5B). CCR2 ${ }^{+}$inflammatory monocytes $\left(\mathrm{CD} 45^{+} \mathrm{CCR} 2^{+} \mathrm{Ly}_{6 \mathrm{C}^{+}}\right)$, which showed higher levels of P2ry6 transcript than BAL fluid cells, infiltrated into the lung after the second sensitizing dose of $D f$, but they were negative for IL-12p40 (Supplemental Figure 9, B and C).

To confirm that macrophage-intrinsic $\mathrm{UDP} / \mathrm{P} 2 \mathrm{Y}_{6}$ receptor signaling mediated the early $D f$-induced production of IL-12p40, we modified an AM transplantation protocol that does not involve myeloablation (35). BMMs were derived in vitro from the BMs of $+/+$ and $P 2 r y 6^{f l / f / C r e /+}$ mice in the presence of M-CSF and GM-CSF. Two million BMMs were delivered intratracheally to cohorts of recipient $P 2 r y 6^{f / f l / C r e /+}$ mice. Fifteen days later, the engrafted mice were sensitized with $D f$, and quantities of IL-12p40 were measured on day 2 (Figure 6A). qPCR of BAL fluid cells confirmed the presence of the $P 2 r y 6$ transcript in recipients of $+/+$ macrophages, albeit at lower levels than in $+/+$ mice (Figure 6B). Df-treated $P 2 r y 6^{f / f / / C r /+}$ recipient mice engrafted with $+/+$ BMMs showed markedly increased levels of IL-12p40 in the BAL fluid compared with $P 2 r y 6^{f / f l / C r e /+}$ recipient mice engrafted with $P 2 r y 6^{f / f l / C r e /+}$ BMMs, approximating the levels observed in $D f-$ treated $+/+$ controls (Figure $6 \mathrm{C}$ ). In contrast, P2ry $6^{f / f / / / \mathrm{Cre} /+}$ mice receiving $P 2 r y 6^{f / f / / C r e /+}$ BMMs showed much lower levels of BAL fluid IL-12p40. Additionally, recipients of $+/+$ BMMs, but not recipients of $\mathrm{P} 2 \mathrm{ry} 6^{\mathrm{fl} / \mathrm{f} / \mathrm{Cr} /+} \mathrm{BMMs}$, showed increased percentages of neutrophils (Figure 6, D and E), increased levels of MPO in BAL fluid (Figure 6F), and increased levels of Mpo mRNA in BAL fluid cells (Figure 6G) after 2 sensitizing doses of $D f$.

$P 2 Y_{6}$ receptor signaling potentiates dectin-2-dependent $I L-12 p 40$ generation by macrophages in response to $D f$. To determine whether $\mathrm{UDP} / \mathrm{P} 2 \mathrm{Y}_{6}$ receptor signaling directly altered IL-12p40 generation by macrophages, we treated BMMs from $+/+$ and $P 2 r y 6^{f / f / / \mathrm{Cre} /+}$ mice with UDP and $D f$. UDP alone was unable to increase the secretion of IL-12p40 from BMMs (Supplemental Figure 10A). However, $D f$-induced secretion of IL-12p40 by $+/+$ BMMs was amplified after UDP priming for 6 hours. This UDP priming effect was abolished in BMMs from $P 2 r y 6^{f / f / / / C r e /+}$ mice.
Secretion of IL-12p40 by BMMs corresponded to their expression of $I l 12 b$ transcript (Supplemental Figure 10A). In contrast, UDP failed to potentiate IL-12p40 production when the order of administration was reversed (Supplemental Figure 10A). We next conducted intrapulmonary challenges of $+/+$ mice with UDP on days 0 and 1 , or before (day 0 ) or after (day 1 ) a single sensitizing dose of $D f$ to determine whether it directly altered IL-12p40 generation in vivo. UDP alone on days 0 and 1 did not increase BAL fluid IL-12p40 levels, nor did it increase the quantities of $D f$ induced IL-12p40 when administered 24 hours after a single sensitizing dose (Supplemental Figure 10B). In contrast, administration of UDP on day 0 strongly potentiated the production of IL-12p40 induced by a single dose of $D f$ administered on day 1, with quantities approaching those generated in response to 2 sensitizing doses of $D f$. UDP failed to potentiate $D f$-induced IL-12p40 production in $P 2 r y 6^{f / f / / C r e /+}$ mice. UDP also potentiated LPS-induced IL-12p40 generation by BMMs, although this effect was similar in $+/+$ and P2ry $6^{f / f / / / C r e /+}$ BMMs (Supplemental Figure 10C). To identify the receptor(s) for $D f$ on macrophages required for IL-12p40 production, we administered sensitizing doses of $D f$ to mice lacking Dectin-2 (Clec $4 n^{-/}$mice), a C-type lectin receptor involved in innate immune recognition of carbohydrate structures associated with complex allergens (3). Compared with WT control mice, Clec $4 n^{-/}$mice showed lower percentages of IL-12p $40^{+} \mathrm{CD}^{-1} 8^{+} \mathrm{BAL}$ fluid cells but similar increases in BAL fluid UDP levels (Supplemental Figure 11, A-C). From these experiments, we concluded that UDP/P2Y ${ }_{6}$ signaling synergizes with allergen-derived signals to induce IL-12 production by AMs.

Macrophage- and $\mathrm{P}^{2} \mathrm{Y}_{6}$-dependent IL-12 drives an early IFN- $\gamma$ signature that depends on NK cells. IFN- $\gamma$ is a known effector downstream of IL-12 signaling that counteracts T2I and polarizes macrophages to an M1-type phenotype. To determine whether Df sensitization elicited an IFN- $\gamma$ signature in the alveolar space, we examined BAL fluid cells from $D f$-sensitized $+/+$ and $P 2 r y 6^{f / f / / \mathrm{Cre} /+}$ mice for markers of IFN- $\gamma$-induced transcription. Cells from $P 2 r y 6^{f / f / / \mathrm{Cr} /+}$ mice, compared with $+/+$ mice, expressed significantly lower levels of mRNA transcripts associated with M1 macrophage polarization and/or IFN- $\gamma$ signatures, including Ccl5, Cxcl9, Cxcl10, Cxcl11, Ccl22, and Socs1 (Supplemental Table 1A). These were restored to near $+/+$ levels by transfer of macrophages from $+/+$ but not $P 2 r y 6^{f / f l / C r e /+}$ mice and i.n. restoration of IL-12p70 (Supplemental Table 1, B and C), and were potentiated by a priming dose of UDP in WT mice (Supplemental Table 2) prior to $D f$ sensitization. Ifng mRNA was strongly induced in BAL fluid cells from $+/+$ mice after 2 challenge doses of $D f$ but was not induced in $P 2 r y 6^{f / f / / C r /+}$ mice (Figure 7A). In contrast, whole-lung Ifng mRNA did not change with sensitization and did not differ between the strains. Transfer of $+/+$ but not $P 2 r y 6^{f / f l / C r e /+}$ macrophages restored $D f$-induced Ifng expression to BAL fluid cells from $P 2 r y 6^{f / f / / / C r e /+}$ mice (Figure $7 \mathrm{~B}$ ). In BAL fluid cells of $\mathrm{P} 2 r y 6^{\mathrm{fl} / \mathrm{f} / \mathrm{Cre} /+}$ mice, administration of exogenous IL-12p70 also restored Ifng expression, which was limited to the $\mathrm{CD} 11 \mathrm{c}^{-}$cell fraction (Figure 7C). We administered exogenous recombinant IL-12p70, IL-12p80 (IL-12p40 homodimer), and IL-23 i.n. to WT mice on 2 successive days or after a single sensitizing dose of $D f$ to determine whether they would induce IFN- $\gamma$ production in vivo (Supplemental Figure 12A). IL-12p70, but not IL-12p80 or IL-23, 
significantly increased Ifng expression by BAL fluid cells in both treatments. Only administration of IL-23 after a single sensitizing dose of $D f$ induced $I l 17 a$ gene expression (Supplemental Figure 12B). In contrast, treatment with a neutralizing anti-IL-12R $\beta 2 \mathrm{mAb}$ directed against a specific subunit of the IL-12p70 receptor significantly decreased recombinant IL-12p70-induced (ex vivo) and $D f$-induced (in vivo) Ifng transcript levels in BAL fluid cells (Supplemental Figure 12C). To determine whether IFN- $\gamma$ production at sensitization was essential for $\mathrm{P} 2 \mathrm{Y}_{6} / \mathrm{IL}-12$-dependent suppression of T2I on day 16, we sensitized Ifng $g^{-/}$mice and WT controls with $D f$ and compared their responses with subsequent $D f$ challenges. Compared with WT controls, Ifng $\mathrm{g}^{-/}$mice showed sharply increased numbers of BAL fluid total cells, eosinophils, and neutrophils on day 16 (Figure 7D). Histological examination confirmed that bronchovascular inflammation in Df-sensitized and -challenged Ifng ${ }^{-1}$ mice was more extensive than in WT controls (Figure 7E). Serum IgG2c was nearly undetectable in Ifng ${ }^{-/}$mice (Figure $7 F$ ). Levels of IL-4, IL-5, and IL-13 in BAL fluid and BAL fluid cell expression of Il4 and Il13 were significantly higher in Ifng ${ }^{-/}$mice than in WT controls (Figure 7G and Supplemental Figure 13).

To identify the major cell source(s) of protective IFN- $\gamma$ present at sensitization, we focused on the Ly $6 \mathrm{G}^{-}$lymphocyte population (CD11c $\mathrm{c}^{-}$population) that was recruited to the alveolar spaces of sensitized $+/+$ mice and that was largely absent in $P 2 r y 6^{f / / f / / C r e /+}$ mice (Figure 5A, bottom panels). We identified 4 populations within these lymphocytes based on staining for CD3 and NK1.1, with the 2 most abundant groups being $\mathrm{CD}^{-}{ }^{-} \mathrm{NK} 1.1^{+}$and $\mathrm{CD}^{+} \mathrm{NK} 1.1^{-}$, respectively (Figure 8A). Both the $\mathrm{CD}^{-} \mathrm{NK} 1.1^{+}$and $\mathrm{CD}^{+} \mathrm{NK} 1.1^{+}$ subsets strongly expressed Ifng (relative to Gapdh), but the CD3 $\mathrm{NK} 1.1^{+}$subset was the dominant source of the transcript based on the differences in cell numbers (Figure 8A). The CD3-NK1.1 ${ }^{+}$ subset also showed greater mRNA expression of IL-12R $\beta 2$ (Supplemental Figure 14A). Intranasal administration of an anti-NK1.1 $\mathrm{mAb}$, which recognizes NK and NKT cells, substantially decreased the quantity of Ifng mRNA transcripts detected in BAL fluid cells (Figure 8B). BAL fluid cells from $C d 1 d^{-/}$mice lacking NKT cells showed no decrement in $D f$-induced Ifng expression compared with WT controls (Figure 8C). Anti-NK1.1 treatment selectively depleted $\mathrm{CD}^{-} \mathrm{CD}^{-} 9 \mathrm{~b}^{+}$and $\mathrm{CD}^{-} \mathrm{NKp} 46^{+}$lymphocyte populations from the BAL fluid, and sharply decreased expression of $\mathrm{Nkg} 2 \mathrm{~d}$, without altering the numbers of $\mathrm{CD}^{+}$cells or expression of $\mathrm{Il} 2$ (Supplemental Figure 14, B and C). Compared with $D f$-sensitized $+/+$ mice, BAL fluid from $P 2 r y 6^{f / f / / / C r e /+}$ mice contained markedly decreased numbers of $\mathrm{CD}^{-} \mathrm{NK} 1.1^{+}$and $\mathrm{CD}^{-}{ }^{-} \mathrm{Nkp} 46^{+}$cells, as well as fewer $\mathrm{CD}^{+}$cells (Figure 8D). Treatment of WT mice with i.n. anti-NK1.1 during sensitization sharply increased BAL fluid total cell and eosinophil counts, bronchovascular inflammation, and type 2 cytokine expression after $D f$ challenge compared with WT mice receiving the isotype control (Figure $8 \mathrm{E}$ and Supplemental Figure 14D). In contrast, anti-NK1.1 at sensitization did not alter the expression of Ifng or $N k g 2 d$ in BAL fluid cells after $D f$ challenge on day 16. $D f$-challenged NKT cell-deficient $C d 1 d^{-/-}$and WT mice showed similar numbers of BAL fluid eosinophils on day 16 (Supplemental Figure 14E). We concluded from these experiments that IFN- $\gamma$-producing NK cells, and not NKT cells, were the major downstream targets of the $\mathrm{P}_{2} \mathrm{Y}_{6}$-dependent, AM-derived IL-12 involved in the suppression of inappropriate type 2 responses.
CysLT $R$ antagonists suppress early $P 2 Y_{6}$ receptor-dependent signaling and $I L-12 p 40$ generation that counterbalances $C y s L T_{1} R$ induced T2I priming function. $\mathrm{P} 2 \mathrm{Y}_{6}$ receptors are structural homologs of the cysLT-specific GPCRs CysLT ${ }_{1} R$, CysLT $_{2} R$, and CysLT ${ }_{3} R$ $(18,20)$. CysLT $R$ is central to Dectin-2-mediated DC priming for T2I (33), and clinically active antagonists of this receptor can block $\mathrm{P} \mathrm{Y}_{6}$ receptor signaling in transfected cells (21). We sought to determine whether CysLT ${ }_{1}$ R antagonists block natively expressed $\mathrm{P} 2 \mathrm{Y}_{6}$ receptors, and if so whether this blockade modifies protective $\mathrm{P}_{2} \mathrm{Y}_{6}$ receptor signaling at the initiation of $\mathrm{T} 2 \mathrm{I}$ in vivo. The CysLT $_{1} \mathrm{R}$ antagonists montelukast, zafirlukast, pranlukast, and MK-571 all inhibited UDP-elicited calcium flux in 1321N1 cells stably expressing mouse P2ry6 (montelukast, zafirlukast, and pranlukast) or the macrophage cell line RAW 264.7 (MK-571) (Figure 9A). All 4 antagonists also blocked the UDP-elicited potentiation of $D f$-induced IL-12p40 generation by BMMs (Figure 9B). Montelukast also reduced IL-12p40 generation in response to $D f$ alone at the highest dose tested. Exogenous $\mathrm{LTC}_{4}, \mathrm{LTD}_{4}$, and $\mathrm{LTE}_{4} \mathrm{did}$ not potentiate IL-12p40 production by BMMs, and UDP did not induce cysLT generation by BMMs (data not shown). Administration of either zafirlukast (i.p.) or MK-571 (i.n.) to WT mice during $D f$ sensitization significantly reduced the concentration of IL-12p40 in BAL fluid and decreased expression of Ifng by BAL fluid cells (Figure 9C). IL-12p40 levels and Ifng transcripts were tightly correlated (Figure 9C). Administration of zafirlukast at sensitization markedly decreased the numbers of BAL fluid total cells, eosinophils, and neutrophils, bronchovascular inflammation, and type 2 cytokine and Epx expression induced by $D f$ on day 16 in $P 2 r y 6^{f / f l / C r e /+}$ mice, but did not affect the modest levels seen in $+/+$ controls (Figure 9D and Supplemental Figure 15, A and B).

\section{Discussion}

Innate responses of tissue-resident cells to allergens and pathogens instruct subsequent adaptive immune responses, and determine whether subsequent encounters with the same antigens and pathogens will elicit T2I. The broad distribution of P2 receptors (36) - and the availability of their ligands resulting from cellular damage, stress, or activation - suggests the potential for P2 receptor signaling in innate immunity. While the role of ATP in the initial sensitization stage of T2I is well recognized $(4,22)$, less is known about the role of UDP and its cognate receptor. Extracellular concentrations of uracil nucleotides are lower than those of ATP (37), but the high affinity of $\mathrm{P}_{2} \mathrm{Y}_{6}$ receptors and their expression by both structural and hematopoietic cells of the lung suggest that these cells are highly sensitive to extracellular UDP. While pharmacologic blockade of $\mathrm{P}_{2} \mathrm{Y}_{6}$ receptors blunts $\mathrm{T} 2 \mathrm{I}$ in sensitized mice (26), genetic deletion of $\mathrm{P}_{2} \mathrm{Y}_{6}$ receptors sharply enhances T2I and associated eosinophilic inflammation in response to repetitive, low-dose inhalation challenges with $D f$, an allergen strongly linked to asthma in humans (31). Moreover, selective agonism of $\mathrm{P}_{2} \mathrm{Y}_{6}$ receptors suppresses inflammation and airway reactivity in mice (32). We therefore undertook this study to understand the mechanisms and cellular targets that account for the apparent protective effects of $\mathrm{P}_{2} \mathrm{Y}_{6}$ receptor signaling in the lung, and to explain the contradictory results. Moreover, we sought to determine the potential consequences of off-target P2 ${ }_{6}$ blockade by clinically available CysLT ${ }_{1} \mathrm{R}_{\text {antagonists in vivo, }}$ 
particularly in a context where endogenous cysLTs play a major role in sensitization for T2I.

We modified our protocol to incorporate temporally distinct sensitization and challenge phases to account for the possibility that $\mathrm{P} 2 \mathrm{Y}_{6}$ receptors may serve very different functions during the initial and subsequent responses to antigen exposure (Figure 1A). Deletion of P2ry6 prior to the sensitization phase in this modified model mirrored the enhanced lung T2I in the P2ry $6^{f / f / / \mathrm{Cre} /+}$ mice that we had observed in our prior studies using a protocol without distinct sensitization and challenge phases (ref. 31 and Figure 1). In contrast, deletion of P2ry6 after sensitization sharply reduced eosinophilia and type 2 cytokine production (Figure 1). Levels of mRNA encoding Il6 and the CXCR2 ligand Cxcl1 (both of which were previously identified as major $\mathrm{P}_{2} \mathrm{Y}_{6}$ receptor-driven products of lung epithelium [ref. 26]) were significantly reduced in the lungs of $P 2 r y 6^{f / f / / C r /+}$ mice subjected to gene deletion after, but not before, sensitization (Supplemental Figure 5). Combined with the observed increase in BAL fluid UDP occurring within 3 hours of the initial sensitizing dose of $D f$ (Figure 3D), these observations support an early (and likely innate) cellular target of P2Y receptor activation as a prime modifier of the subsequent immune response. Our bioassay showed that $\mathrm{P}_{2} \mathrm{Y}_{6}$-induced calcium flux induced by BAL fluids completely disappeared after pretreatment with the nucleotide-hydrolyzing enzyme apyrase (Supplemental Figure 7B). Although we cannot exclude the possibility that nucleotides other than UDP activate the $\mathrm{P}_{2} \mathrm{Y}_{6}$ receptor in vivo, UTP (which is rapidly converted to UDP in vivo) and ADP showed more than 30 and 300 times lower affinity, respectively, than UDP for mouse $\mathrm{P}_{2} \mathrm{Y}_{6}$ (Supplemental Figure 7D). It is thus likely that UDP is the most relevant ligand driving the activation of $\mathrm{P} 2 \mathrm{Y}_{6}$ receptors. While the effector function of $\mathrm{P}_{2} \mathrm{Y}_{6}$ receptors in the challenge phase may well reflect control of epithelial cell-derived proinflammatory factors, as suggested by previous studies (26), the basis of its protective functions during sensitization became the focus of our subsequent experiments.

We used a combination of conditionally gene-deleted mice and cell transfers to identify the target cells and mechanisms responsible for the protective effect of $\mathrm{P} 2 \mathrm{Y}_{6}$ receptors in the sensitization phase. Scgb1a1-driven P2ry6 deletion failed to potentiate inflammation, indicating that the protective effect of $\mathrm{P} 2 \mathrm{Y}_{6}$ receptor signaling was not due to Clara cell-intrinsic signaling (Figure 2A). Although we had previously demonstrated that $\mathrm{P} 2 \mathrm{Y}_{6}$ receptors were inducibly expressed by $\mathrm{CD} 4^{+}$and $\mathrm{CD} 8^{+} \mathrm{T}$ cells after challenge with $D f(31)$, constitutive $C d 4$-driven $P 2 r y 6$ deletion (which eliminates gene expression at the double-positive state of thymic T cell development) did not recapitulate the effect of global P2ry6 deletion proximal to sensitization (Figure 2B). Results of experiments involving adoptive transfer of BM into lethally irradiated mice not only supported the involvement of $\mathrm{P} 2 \mathrm{Y}_{6}$ receptors expressed by hematopoietic cells in the protective response (Figure $2 \mathrm{C}$ ), but also revealed that hematopoietic cells accounted for approximately $80 \%$ of the P2ry6 transcript expressed by the lung on day 16. We therefore focused our attention on the potential role of $\mathrm{P} 2 \mathrm{Y}_{6}$ receptors on lung-resident hematopoietic cells and on whether $\mathrm{P} 2 \mathrm{Y}_{6}$ receptor signaling was critical to their generation of products that regulate immune responses during the initial exposure to antigens.
Macrophages and $\mathrm{CD}^{+}$DCs, the innate hematopoietic cells most strongly expressing $\mathrm{P} \mathrm{Y}_{6}$ receptors (http://rstats.immgen. org/Skyline/skyline.html), generate cytokines on initial encounters with antigens that can inform adaptive responses. IL-12 generated at sensitization has a known protective effect against inappropriate T2I (38), although the cell sources and regulatory mechanisms are not fully understood. Our study indicates that $\mathrm{UDP} / \mathrm{P} \mathrm{Y}_{6}$ signaling facilitates IL-12 generation by AMs as a prominent component of $\mathrm{P}_{2} \mathrm{Y}_{6}$-dependent protection from T2I. BAL fluid levels of IL-12p40 (a subunit of both IL-12 and IL-23), but not levels of IL-23, IL-10, or IL-18, increased shortly after administration of sensitizing doses of $D f$ in $+/+$ but not $P 2 r y 6^{f / f / / C r /+}$ mice, without corresponding changes in serum IL-12p40 (Figure 3C). This increase occurred concomitantly with increases in UDP (Figure 3D). Restoring physiologic concentrations of IL-12 at sensitization (Figure 4A) decreased BAL fluid total cell and eosinophil counts (Figure 4B) and tissue Epx expression (Figure $4 \mathrm{C}$ ) in $P 2 r y 6^{f / f / / \mathrm{Cre} /+}$ mice to levels similar to those observed in $+/+$ controls, and also increased serum IgG2c in $P 2 r y 6^{f / f / / / C r e /+}$ mice to $+/+$ levels (Figure 4D) (in retrospect, a likely reflection of IFN- $\gamma$ ). $D f$ sensitization increased expression of IL-12p40 protein specifically in $\mathrm{CD}_{68}{ }^{+} \mathrm{CD} 11 \mathrm{c}^{+} \mathrm{AMs}$ in a $\mathrm{P} \mathrm{Y}_{6}$ receptor-dependent manner (Figure 5A and Supplemental Figure 9), with minimal contributions from interstitial macrophages, DCs, and granulocytes (Figure $5 \mathrm{~B}$ ). Finally, transfer of macrophages derived from the $\mathrm{BM}$ of $+/+$, but not $P 2 r y 6^{f / f / / / \mathrm{Cr} /+}$, mice restored early $D f$-induced IL-12p40 (Figure 6), along with $D f$-induced neutrophil recruitment. Although exogenous UDP was insufficient alone to induce IL-12p40 generation, it substantially primed macrophages ex vivo and in vivo (Supplemental Figure 10) for $D f$-induced IL-12p40 generation. The absence of Df-induced IL-12p40 in AMs of Clec $4 n^{-/-}$mice (Supplemental Figure 11) supports the argument that branched mannans associated with $D f$ act as direct ligands for Dectin-2 on macrophages (3) as they do on DCs (3). Notably, other major "Th2-sensitizing” allergens, such as those associated with Dermatophagoides farinae and Aspergillus fumigatus, require Dectin-2 signaling on DCs to elicit sensitization of Th2 cells and subsequent T2I (33). Our studies suggest that P2Y 6 signaling facilitates Dectin-2-dependent AM activation, counteracting Th2 sensitization and its consequences through early generation of IL-12p40. Moreover, macrophage- and P2Y -driven IL-12 is necessary to activate a population of NK cells that provide IFN- $\gamma$ to counteract subsequent T2I at the challenge phase (Figures 7 and 8).

IL-12p40 can homodimerize to form IL-12p80, or can pair with IL-12p35 or IL-23p19 to form IL-12p70 or IL-23, respectively. Although we did not detect IL-12p70 (a known inducer of IFN- $\gamma$ responses) in BAL fluid, we found a marked correlation between BAL IL-12p40 and IFN- $\gamma$ production (Supplemental Figure 12A and Figure 9C). Our data suggest that IL-12p80 and IL-23 do not contribute to the innate Th1-like immune response during the sensitization phase (Supplemental Figure 12A). Exogenous IL-23, but not IL-12p70 or IL-12p80, induced IL-17a expression by BAL fluid cells (Supplemental Figure 12B). IL-17a expression was not induced by $D f$ or $\mathrm{P}_{2} \mathrm{Y}_{6}$ during the sensitization phase (data not shown). Moreover, neutralizing anti-IL-12R $\beta 2$ (a subunit of the IL-12p70 receptor) mAb inhibits the recombinant IL-12p70induced (ex vivo) and $D f$-induced (in vivo) Ifng expression detected in BAL fluid cells (Supplemental Figure 12C). Although these data 
support the functional contribution of IL-12p70 to Ifng expression, we cannot exclude contributions from other $\mathrm{P}_{2} \mathrm{Y}_{6}$-regulated pathways. Indeed, levels of Th1/M1 cytokines/chemokines from AMs (including several that act on NK cells) were also decreased in $P 2 r y 6^{f / f / / C r e /+}$ mice (Supplemental Table 1). Further investigations are needed to determine the potential contributions from these cytokines and chemokines to the integrated $\mathrm{P}_{2} \mathrm{Y}_{6}$-regulated IFN- $\gamma$ response.

Clinically active $\mathrm{CysLT}_{1} \mathrm{R}$ antagonists achieve plasma concentrations of $0.5-1.5 \mu \mathrm{M}$ when administered orally to human subjects, which are within the range reported to block human $\mathrm{P} \mathrm{Y}_{6}$ (and other $\mathrm{P} 2 \mathrm{Y}$ receptors) in vitro (21). We confirmed that 4 different CysLT ${ }_{1} \mathrm{R}$ antagonists block calcium flux and potentiation of IL-12p40 elicited by mouse $\mathrm{P}_{2} \mathrm{Y}_{6}$ receptor signaling ex vivo, albeit at higher concentrations than those reported for the human counterpart (Figure 9, A-C). More importantly, administration of 2 different CysLT $_{1} \mathrm{R}$ antagonists significantly impaired the production of IL-12p40 by AMs that leads to IFN- $\gamma$ production by NK cells to $D f$ sensitization, confirming that these drugs also block $\mathrm{P}_{2} \mathrm{Y}_{6}$ receptor signaling in vivo. Several clinically important allergens (Dermatophagoides farinae, Dermatophagoides pteronyssinus, Aspergillus fumigatus) associated with asthma prime DCs for T2I by a Dectin-2/CysLT ${ }_{1}$ R pathway $(3,33)$. Our results suggest that the effects of this pathway are counteracted by Dectin-2/P2 ${ }_{6}$ receptor signaling, and that absence or impairment of the latter pathway magnifies the effects of the former (and hence the ability of CysLT $_{1} \mathrm{R}$ antagonists to block T2I). CysLT $_{1} \mathrm{R}$ antagonists are FDA approved to treat asthma and rhinitis in children as young as 6 months (39). The incidence of de novo sensitization to inhalant antigens is high in children. Our findings could help to explain the widely variable individual responses to CysLT $_{1} \mathrm{R}$ antagonists (15), and suggest that the development of drugs with greater selectivity for CysLT ${ }_{1} \mathrm{R}$ (or CysLT ${ }_{1} \mathrm{R}$ antagonists with $\mathrm{P}_{2} \mathrm{Y}_{6}$ receptor agonism) would confer a more robust and consistent therapeutic effect by protecting susceptible populations from T2I sensitization.

\section{Methods}

Further information can be found in Supplemental Methods, available online with this article.

Animals. $P 2 r y 6^{f / / f /+/+}$ mice and $P 2 r y 6^{f / f / / C r e /+}$ mice were derived as previously reported and backcrossed for 10 generations with C57BL/6 mice (31). To delete the $\mathrm{P} \mathrm{Y}_{6}$ receptor ubiquitously, we induced Rosa26 Cre recombinase in 10- to 19 -week-old P2ry $6^{f / / / / / C r e /+}$ mice (as shown in Figure 1C, Figures 3-8, and the supplemental figures) by administration of tamoxifen (1 mg; MilliporeSigma) dissolved in a mixture of ethanol/sunflower seed oil (1:4.5, v/v) by i.p. injections on 5 consecutive days (Figure 1A). C57BL/6-P2ry6tm2450Arte mice were intercrossed with $\mathrm{Cd} 4$-Cre mice to generate $P 2 r y 6^{f / f l} \mathrm{Cd} 4-\mathrm{Cre} /+$ mice and with Scgb1a1-Cre mice to generate P2ry6 ${ }^{f / f l}$ Scgb1a1-Cre/+ mice (Figure 2, $\mathrm{A}$ and B) at the University Medical Center Freiburg. Ifng ${ }^{-/}$(B6.129S7Ifng ${ }^{\mathrm{tm} 1 \mathrm{Ts} / \mathrm{J})}$ and $\mathrm{Cd} 1 d^{-/-}$[B6.129S6-Del(3Cd1d2-Cd1d1)1Sbp/J] mice were obtained from the Jackson Laboratory. $\mathrm{Clec} 4 n^{-/-}$mice were provided by Yoichiro Iwakura (Tokyo University of Science, Tokyo, Japan). C57BL/6 controls were obtained from the Jackson Laboratory and Charles River.

Induction of allergic pulmonary inflammation and in vivo injection. Ten days after the last administration of tamoxifen, allergic pulmo- nary inflammation was induced in $+/+$ and $P 2 r y 6^{f / f / / C r e /+}$ mice by separate sensitization ( $20 \mu \mathrm{g}$ i.n. on days 0 and 1$)$ and challenge ( $3 \mu \mathrm{g}$ i.n. on days 14 and 15) with $D f$ (Greer Laboratories). Control groups of + /+ and $P 2 r y 6^{f / f l / C r /+}$ mice received $0.9 \% \mathrm{NaCl}$ alone. After the $D f$ treatment, mice were euthanized, and blood was collected by cardiac puncture and centrifuged to obtain serum. Lungs were lavaged 2 times with 1.0 mL PBS containing 0.5 mM EDTA. BAL fluid cells were cytocentrifuged onto slides, stained with Diff-Quick (Siemens Healthcare Diagnostics Inc.), and differentially counted. Left lungs were collected at the time of euthanasia, fixed with $4 \%$ PFA overnight, and embedded in glycol methacrylate. Sections were stained with H\&E as previously reported (40). Light microscopic images were captured using a Leica DM LB2 light microscope with HC PL FLUOTSR 10×/0.30 (H\&E stain) and 40×/0.75 (Diff-Quick stain) objective lens (Leica) and Nikon ACT- 1 software at $22^{\circ} \mathrm{C}$. Pictures were not further adjusted for brightness and contrast.

For restoration of IL-12 protein in the alveolar space, mice received i.n. administered recombinant murine IL-12p70 (500 ng, Thermo Fisher Scientific) on 4 consecutive days during the sensitization phase. For depletion of NK cells in the alveolar space, mice received i.n. administered $10 \mu \mathrm{g}$ anti-NK1.1 (PK136, Thermo Fisher Scientific) or control mouse IgG2 (Thermo Fisher Scientific) on days 0 and 1. Intranasal injection of UDP (MilliporeSigma; $80 \mathrm{nmol}$ in $\mathrm{NaCl}$ ) was performed on days 0 and 1 , or before (day 0 ) or after (day 1 ) a single sensitizing dose of $D f(20 \mu \mathrm{g})$. To study the role of IL-12p40, we i.n. injected IL-12p70, IL-12p80 (p40 homodimer, 500 ng, BioLegend), and IL-23 (500 ng, BioLegend) on days 0 and 1 or after (day 1) a single sensitizing dose of $D f(20 \mu \mathrm{g})$. Intranasal injection of neutralizing mouse IL-12Rß2 antibody (10 $\mu$ g in PBS, R\&D Systems) and control IgG (R\&D Systems) was performed on days 0 and 1 . Zafirlukast (Cayman Chemical) for i.p. injection $(30 \mathrm{mg} / \mathrm{kg})$ was suspended in a $30 \%$ propylene glycol (PG) solution $(70 \% \mathrm{NaCl} / 30 \%$ PG [PG/PEG40/ Tween-80, 4:2:1]) before use. Control mice received the same volume of $30 \%$ PG alone. MK-571 (Cayman Chemical) was dissolved in $\mathrm{NaCl}$ $(100 \mathrm{nmol} / 20 \mu \mathrm{L})$ and administered i.n.

$B M M$ and BM-derived DC generation. For bone BMM generation, BM cells obtained from tamoxifen-treated $+/+$ and $P 2 r y 6^{f / f / / / C r /+}$ mice on day 10 were harvested, and this suspension $\left(4 \times 10^{6}\right.$ cells $\left./ 10 \mathrm{~mL}\right)$ was cultured in DMEM/F12 medium supplemented with $10 \%$ heatinactivated FBS, $100 \mathrm{U} / \mathrm{mL}$ penicillin, $100 \mu \mathrm{g} / \mathrm{mL}$ streptomycin, 2 $\mathrm{mM} \mathrm{L}$-glutamine, and $100 \mathrm{ng} / \mathrm{mL}$ recombinant mouse M-CSF (R\&D Systems). On day 3, $5 \mathrm{~mL}$ complete medium with M-CSF was added, and the adherent cells were harvested on day 6 or 7. For IL-12p40 measurement ex vivo, BMMs were plated in 96-well plates in DMEM/ F12 medium supplemented with $10 \%$ FBS, $100 \mathrm{U} / \mathrm{mL}$ penicillin, and $100 \mu \mathrm{g} / \mathrm{mL}$ streptomycin and cultured overnight. BMDCs were generated with GM-CSF, as previously described (3). In brief, BM cells were cultured in RPMI medium with $10 \%$ heat-inactivated FBS, $100 \mathrm{U} / \mathrm{mL}$ penicillin, $100 \mu \mathrm{g} / \mathrm{mL}$ streptomycin, $2 \mathrm{mM} \mathrm{L-}$ glutamine, $50 \mu \mathrm{M}$ 2-mercaptoethanol, and $20 \mathrm{ng} / \mathrm{mL}$ recombinant mouse GM-CSF (Peprotech). On day 3, $10 \mathrm{~mL}$ complete medium with GM-CSF was added, and on day 6,10 mL medium with GM-CSF was exchanged from each plate. The floating cells were harvested on day 7.

Flow cytometry. Mouse lungs were transferred into a 6-well dish, and tissue was teased apart with forceps. Then the tissues were digested at $37^{\circ} \mathrm{C}$ for 30 minutes in RPMI containing $428 \mathrm{U} / \mathrm{mL}$ Collagenase IV 
(Worthington) and $20 \mu \mathrm{g} / \mathrm{mL}$ DNAse I (Roche). Cells were filtered through $70-\mu \mathrm{m}$ nylon meshes and pelleted by centrifugation for $5 \mathrm{~min}$ utes at $350 \mathrm{~g}$ at $4^{\circ} \mathrm{C}$. RBC lysis was performed by resuspending the pellet in $5 \mathrm{~mL} \mathrm{RBC} \mathrm{lysis} \mathrm{buffer} \mathrm{(BioLegend)} \mathrm{and} \mathrm{incubating} \mathrm{on} \mathrm{ice} \mathrm{for} 4 \mathrm{~min}$ utes; this was terminated by addition of $10 \mathrm{~mL}$ PBS. Cells were centrifuged for 5 minutes at $350 \mathrm{~g}$ at $4^{\circ} \mathrm{C}$ and washed with FACS buffer $(0.5 \%$ BSA in HBSS). A total of $1 \times 10^{6}$ cells were blocked ( 15 minutes, $\left.4^{\circ} \mathrm{C}\right)$ with $1 \%$ anti-mouse CD16/CD32 (BioLegend) and stained with cell surface markers: CD45-PerCP/Cy5.5, CD24-BV421, CD11c-PE-Cy7, CD11bAPC-Cy7, and Siglec F-PE. Cells were washed and fixed/permeabilized with a BD Cytofix/Cytoperm kit (BD Biosciences) and then stained with IL-12(p40/p70)-APC (overnight, $4^{\circ} \mathrm{C}$ ). For IL-12p40 staining in BAL fluid cells, collected BAL cells were washed and immediately fixed/ permeabilized with a BD Cytofix/Cytoperm kit. Cells were blocked (15 minutes, $4^{\circ} \mathrm{C}$ ) with $1 \%$ anti-mouse CD16/CD32 and stained with appropriate antibodies: IL-12(p40/p70)-PE, CD45-BV421, CD68-APC, Ly-6G-BV510, and CD11c-PE-Cy7 (overnight, $4^{\circ} \mathrm{C}$ ). Lymphocytes in BAL fluid were stained with Zombie Aqua Fixable Viability Kit (BioLegend) according to the manufacturer's protocol, blocked ( 15 minutes, $4^{\circ} \mathrm{C}$ ) with $1 \%$ anti-mouse $\mathrm{CD} 16 / \mathrm{CD} 32$, and stained $\left(30\right.$ minutes, $\left.4^{\circ} \mathrm{C}\right)$ with a cell surface marker: CD45-BV421, CD335(Nkp46)-APC, NK1.1-APCvio770, CD3-PE-Cy7 or CD3-APC-Cy7, and CD49b-PE-Cy7. Analyses were performed on a FACSCanto flow cytometer or FACS Fortessa analyser (BD Biosciences). Data were analyzed with FlowJo (TreeStar). Antibodies used are listed in Supplemental Table 3.

Real-time qPCR of mRNA transcripts. Right lung, spleen, lymph node, BM, and BAL cells were collected at time of euthanasia and snap-frozen. AMs were purified from BAL of $D f$ - and IL-12-treated mice by positive CD11c MACS selection (Miltenyi Biotec), according to the manufacturer's protocol. AM purity was checked by staining with Diff-Quick and was confirmed to be greater than 95\%. Sorting of $\mathrm{CD}^{-}{ }^{-} \mathrm{NK} 1.1^{+}, \mathrm{CD}^{+} \mathrm{NK} 1.1^{-}, \mathrm{CD}^{+} \mathrm{NK} 1.1^{+}$, and $\mathrm{CD}^{-} \mathrm{NK} 1.1^{-}$(NK1.1APC, CD3-PE) cells in BAL fluid cells, CCR2 inflammatory monocytes (CCR2-PE', Ly6C-APC ${ }^{+}, \mathrm{CD} 45-\mathrm{BV} 421^{+}$), T cells (CD45-BV421', CD3-PE ${ }^{+}, \mathrm{CD} 90-\mathrm{APC}^{+}$), and ILCs (CD45-BV421', Lin-FITC ${ }^{-}, \mathrm{CD} 90-$ $\left.\mathrm{APC}^{+}\right)$in dispersed lungs was performed using a FACSDiva 8.0.1 cell sorter (BD Biosciences). Total RNA was isolated from tissue homogenate, BAL cells, BMDCs, BMMs, and sorted cells with QIAzol reagent (QIAGEN). For a few cells, glycogen (RNA grade, Thermo Fisher Scientific) was used as an inert carrier to increase nucleic acid recovery from alcohol precipitation. Total RNA was converted to cDNA using an $\mathrm{RT}^{2}$ First Strand Kit (QIAGEN). The expression of each gene was examined using an $\mathrm{RT}^{2}$ SYBR Green qPCR Master Mix (QIAGEN). Expression levels of transcripts were normalized to the expression of Gapdh. All primer sequences are listed in Supplemental Table 4.

UDP bioassay and calcium flux. We transfected 1321N1 cells (gift from Y. Kanaoka, Brigham and Women's Hospital) with the mouse P2ry6 expression plasmid (pEF1-mouse P2ry6) using Lipofectamine 2000 (Invitrogen). Stably transfected cells were selected with G418 for more than 21 days. Mouse 1321N1 cells stably expressing P2Y, parental cells, BMMs, and the macrophage cell line RAW 264.7 (ATCC) were cultured in DMEM containing $10 \% \mathrm{FBS}$ at $37^{\circ} \mathrm{C}$ in a $5 \% \mathrm{CO}_{2}$ atmosphere. The cell suspension was plated in a 384-well plate (Greiner Bio-One) at a density of $1 \times 10^{4}$ cells/well. Following incubation for 18-24 hours, cells were changed to fresh HBSS medium and loaded with Fluo-8 (final, $2 \mu \mathrm{M}$; AAT Bioquest), probenecid (final, $2.5 \mathrm{mM}$; Thermo Fisher Scientific), and PowerLoad (Thermo Fisher Scientific) in HBSS. After 30 minutes,
CysLT $_{1}$ antagonists (montelukast, zafirlukast, pranlukast, and MK-571; Cayman Chemical), UDP (MilliporeSigma), and BAL fluid in compound plate (Nunc) were added at defined concentrations, followed by an immediate recording of the fluorescence using the Functional Drug Screening System/FDSS7000EX (Hamamatsu). Fluorescence intensity was expressed as a Fluo-8 ratio (tested value/basal value). Apyrase ( $2 \mathrm{U} /$ $\mathrm{mL}$; MilliporeSigma) was preincubated at $37^{\circ} \mathrm{C}$ for 60 minutes.

ELISA and measurement of EPO. Concentrations of IL-12p40, IL-12p70, IL-23, IL-10, IL-18, MPO, IFN- $\gamma$, cysteinyl leukotrienes, and Igs (total IgE, IgG2c, and IgM) in BAL, serum, and supernatants from the ex vivo BMMs were assayed by using commercially available ELISA kits according to the instructions of manufacturers BD Biosciences (IL-12p40 and IFN- $\gamma$ ), BioLegend (IL-12p70), R\&D Systems (MPO), Peprotech (IL-10), Cayman Chemical (cysteinyl leukotrienes), and Thermo Fisher Scientific (IL-18, IL-23, and Igs). EPO in BAL supernatants was analyzed as previously reported (41). In brief, $50 \mu \mathrm{L}$ BAL was mixed with $100 \mu \mathrm{L}$ substrate $(0.2 \mathrm{mg} / \mathrm{mL} o$-phenylenediamine in Tris, $\mathrm{pH} 8.0$, including $0.1 \%$ Triton and $0.02 \% \mathrm{H}_{2} \mathrm{O}_{2}$ ) in 96-well plates. The reaction was allowed to progress for 30 minutes before being quenched with $50 \mu \mathrm{L}$ of $4 \mathrm{M}$ sulfuric acid. Plates were read at $490 \mathrm{~nm}$ with a plate reader.

Adoptive transplantation of $B M$. Adoptive transplantation of $\mathrm{BM}$ was performed as described previously (42). +/+ and P2ry $6^{f / f / / \mathrm{Cre} /+}$ mice were lethally irradiated $(12 \mathrm{~Gy})$ in 2 split doses on the same day 10 days after the last administration of tamoxifen. Immediately after the second dose of irradiation, recipient mice were injected into the lateral tail vein with $1 \times 10^{7} \mathrm{BM}$ cells in a total volume of $200 \mu \mathrm{L}$ PBS obtained from sex-matched tamoxifen-treated $+/+$ mice and $P 2 r y 6^{f / f / / / C r e /+}$ mice. As a result of the BM transfer, 4 groups of chimeric mice were generated: $+/+\mathrm{BM}$ into $+/+$ mice $(+/+\rightarrow+/+),+/+\rightarrow P 2 r y 6^{f / f f / / \mathrm{Cre} /+}$ mice, $P 2 r y 6^{f / f / / C r e /+} \rightarrow+/+$ mice, and $P 2 r y 6^{f / f / / C r e /+} \rightarrow P 2 r y 6^{f / f / / / C r e /+}$ mice. Ten weeks after the adoptive transplantation of $\mathrm{BM}$, allergic pulmonary inflammation was induced by i.n. instillation of $D f$, as described above.

Pulmonary macrophage transplantation. AM transplantation was performed as described previously (35). BM cells obtained from tamoxifen-treated $+/+$ and $P 2 r y 6^{A / f / / C r e /+}$ mice on day 10 were harvested, and this suspension $\left(27 \times 10^{6}\right.$ cells $\left./ 10 \mathrm{~mL}\right)$ was cultured in DMEM medium supplemented with $10 \%$ heat-inactivated FBS, $100 \mathrm{U} / \mathrm{mL}$ penicillin, $100 \mu \mathrm{g} / \mathrm{mL}$ streptomycin, $2 \mathrm{mM}$ L-glutamine, and $10 \mathrm{ng} / \mathrm{mL}$ recombinant mouse GM-CSF and $5 \mathrm{ng} / \mathrm{mL}$ recombinant mouse $\mathrm{M}-\mathrm{CSF}$ (both from R\&D System). The next day, non- or weakly adherent cells were transferred to a new petri dish and cultured. After 2 days, $10 \mathrm{~mL}$ medium with GM-CSF and M-CSF was exchanged from each plate; and 5 days after seeding, adherent BM-derived macrophages were used for AM transplantation. Two million BM-derived macrophages in a total volume of $50 \mu \mathrm{L}$ PBS were administered into the lungs of $+/+$ mice and $P 2 r y 6^{A / f / / C r e /+}$ mice using a relatively noninvasive endotracheal instillation method described previously (35). The next day, mice were administered with tamoxifen for 5 consecutive days and 10 days after the last tamoxifen treatment, allergic pulmonary inflammation was induced by i.n. instillation of $D f$, as described above.

Statistics. All values are presented as mean \pm SEM. Figures were produced and statistics analyzed using GraphPad Prism 6 (GraphPad Software). When data were not normally distributed, the MannWhitney $U$ test was used for comparisons of 2 groups. A 2-tailed unpaired $t$ test for equal variance and Welch's correction for unequal variance were used when comparing 2 groups. Differences among multiple groups were 
assessed using 1-way or 2-way ANOVA with Tukey's multiple-comparisons test and nonparametric Kruskal-Wallis test followed by Dunn's post hoc test. $P$ values less than 0.05 were considered statistically significant.

Study approval. All experiments described herein were approved by the Brigham and Women's Hospital IACUC and the Dana-Farber Cancer Institute Animal Care and Utilization Committee.

\section{Author contributions}

JN designed and performed the experiments and analyzed the data. LBF and TK performed experiments. JN developed the UDP assay. $\mathrm{BB}$ provided advice on the macrophage-related experiments. HC and JL provided technical assistance. MI, AZ, EYK, and PJB provided intellectual and strategic input. JAB oversaw the project and experiments, and composed the manuscript with JN.

\section{Acknowledgments}

The authors thank Howard Katz and Juying Lai for histopathologic analysis. This work was supported by contributions from the Vinik Family; the Kaye Family; NIH grants AIO78908, HL111113, HL117945， R37AI052353, R01AI136041， R01HL136209, R01AI130109, and U19AI095219; and an American Heart Association grant (15FTF25080205) awarded to EYK.

Address correspondence to: Joshua A. Boyce, Department of Medicine, Division of Rheumatology, Immunology and Allergy, Brigham and Women's Hospital, Hale Building for Transformative Medicine, 60 Fenwood Road, Room 5002V, Boston, Massachusetts 02115, USA. Phone: 617.525.1261; Email: jboyce@rics.bwh. harvard.edu.
1. Howitt MR, et al. Tuft cells, taste-chemosensory cells, orchestrate parasite type 2 immunity in the gut. Science. 2016;351(6279):1329-1333.

2. Monticelli LA, et al. Innate lymphoid cells promote lung-tissue homeostasis after infection with influenza virus. Nat Immunol. 2011;12(11):1045-1054.

3. Barrett NA, Maekawa A, Rahman OM, Austen KF, Kanaoka Y. Dectin-2 recognition of house dust mite triggers cysteinyl leukotriene generation by dendritic cells. J Immunol. 2009;182(2):1119-1128.

4. Kouzaki H, Iijima K, Kobayashi T, O'Grady SM, Kita $\mathrm{H}$. The danger signal, extracellular ATP, is a sensor for an airborne allergen and triggers IL-33 release and innate Th2-type responses. J Immunol. 2011;186(7):4375-4387.

5. Wang YH, et al. Maintenance and polarization of human TH2 central memory T cells by thymic stromal lymphopoietin-activated dendritic cells. Immunity. 2006;24(6):827-838.

6. Saglani S, et al. IL-33 promotes airway remodeling in pediatric patients with severe steroidresistant asthma. J Allergy Clin Immunol. 2013;132(3):676-685.e13.

7. Hsu Blatman KS, Gonsalves N, Hirano I, Bryce PJ. Expression of mast cell-associated genes is upregulated in adult eosinophilic esophagitis and responds to steroid or dietary therapy. JAllergy Clin Immunol. 2011;127(5):1307-8.e3.

8. Gevaert P, et al. Nasal IL-5 levels determine the response to anti-IL-5 treatment in patients with nasal polyps. J Allergy Clin Immunol. 2006;118(5):1133-1141.

9. Beck LA, et al. Dupilumab treatment in adults with moderate-to-severe atopic dermatitis. N Engl J Med. 2014;371(2):130-139.

10. Bel EH, et al. Oral glucocorticoid-sparing effect of mepolizumab in eosinophilic asthma. $\mathrm{NEnglJ}$ Med. 2014;371(13):1189-1197.

11. Ullah MA, et al. Receptor for advanced glycation end products and its ligand high-mobility group box-1 mediate allergic airway sensitization and airway inflammation. J Allergy Clin Immunol. 2014;134(2):440-450.

12. Weiss JW, et al. Bronchoconstrictor effects of leukotriene C in humans. Science. 1982;216(4542):196-198.

13. Drazen JM, Lilly CM, Sperling R, Rubin P, Israel
E. Role of cysteinyl leukotrienes in spontaneous asthmatic responses. Adv Prostaglandin Thromboxane Leukot Res. 1994;22:251-262.

14. Doherty TA, Khorram N, Lund S, Mehta AK, Croft M, Broide DH. Lung type 2 innate lymphoid cells express cysteinyl leukotriene receptor 1 , which regulates TH2 cytokine production. J Allergy Clin Immunol. 2013;132(1):205-213.

15. Szefler SJ, et al. Characterization of withinsubject responses to fluticasone and montelukast in childhood asthma. J Allergy Clin Immunol. 2005;115(2):233-242.

16. Wada M, Nagata S, Kudo T, Shimizu T, Yamashiro Y. Effect of suplatast tosilate on antileukotriene non-responders with mild-to-moderate persistent asthma. Allergol Int. 2009;58(3):389-393.

17. Rabinovitch N, et al. Urinary leukotriene E4/ exhaled nitric oxide ratio and montelukast response in childhood asthma. J Allergy Clin Immunol. 2010;126(3):545-51.e1.

18. Kanaoka Y, Maekawa A, Austen KF. Identification of GPR99 protein as a potential third cysteinyl leukotriene receptor with a preference for leukotriene E4 ligand. J Biol Chem. 2013;288(16):10967-10972.

19. Communi D, Boeynaems JM. Receptors responsive to extracellular pyrimidine nucleotides. Trends Pharmacol Sci. 1997;18(3):83-86.

20. Mellor EA, Maekawa A, Austen KF, Boyce JA. Cysteinyl leukotriene receptor 1 is also a pyrimidinergic receptor and is expressed by human mast cells. Proc Natl Acad Sci U S A. 2001;98(14):7964-7969.

21. Mamedova L, et al. CysLT1 leukotriene receptor antagonists inhibit the effects of nucleotides acting at P2Y receptors. Biochem Pharmacol. 2005;71(1-2):115-125.

22. Idzko M, et al. Extracellular ATP triggers and maintains asthmatic airway inflammation by activating dendritic cells. Nat Med. 2007;13(8):913-919.

23. Lazarowski ER, Boucher RC. UTP as an extracellular signaling molecule. News Physiol Sci. 2001;16:1-5.

24. Communi D, Parmentier M, Boeynaems JM. Cloning, functional expression and tissue distribution of the human P2Y6 receptor. Biochem Biophys Res Commun. 1996;222(2):303-308.

25. Grbic DM, Degagné E, Langlois C, Dupuis AA,
Gendron FP. Intestinal inflammation increases the expression of the P2Y6 receptor on epithelial cells and the release of CXC chemokine ligand 8 by UDP. J Immunol. 2008;180(4):2659-2668.

26. Vieira RP, et al. Purinergic receptor type 6 contributes to airway inflammation and remodeling in experimental allergic airway inflammation. Am J Respir Crit Care Med. 2011;184(2):215-223.

27. Jin J, Dasari VR, Sistare FD, Kunapuli SP. Distribution of P2Y receptor subtypes on haematopoietic cells. Br J Pharmacol. 1998;123(5):789-794.

28. Maier R, Glatz A, Mosbacher J, Bilbe G. Cloning of P2Y6 cDNAs and identification of a pseudogene: comparison of $\mathrm{P} 2 \mathrm{Y}$ receptor subtype expression in bone and brain tissues. Biochem Biophys Res Commun. 1997;240(2):298-302.

29. Warny M, et al. P2Y(6) nucleotide receptor mediates monocyte interleukin-8 production in response to UDP or lipopolysaccharide. J Biol Chem. 2001;276(28):26051-26056.

30. Bar I, et al. Knockout mice reveal a role for P2Y6 receptor in macrophages, endothelial cells, and vascular smooth muscle cells. Mol Pharmacol. 2008;74(3):777-784.

31. Giannattasio G, Ohta S, Boyce JR, Xing W, Balestrieri B, Boyce JA. The purinergic $\mathrm{G}$ protein-coupled receptor 6 inhibits effector T cell activation in allergic pulmonary inflammation. J Immunol. 2011;187(3):1486-1495.

32. Chetty A, et al. A purinergic P2Y6 receptor agonist prodrug modulates airway inflammation, remodeling, and hyperreactivity in a mouse model of asthma. J Asthma Allergy. 2018;11:159-171.

33. Barrett NA, et al. Dectin-2 mediates Th2 immunity through the generation of cysteinyl leukotrienes. J Exp Med. 2011;208(3):593-604.

34. Tyznik AJ, Verma S, Wang Q, Kronenberg M, Benedict CA. Distinct requirements for activation of NKT and NK cells during viral infection. Jimmunol. 2014;192(8):3676-3685.

35. Suzuki T, et al. Pulmonary macrophage transplantation therapy. Nature. 2014;514(7523):450-454.

36. Burnstock G, Knight GE. Cellular distribution and functions of $\mathrm{P} 2$ receptor subtypes in different systems. Int Rev Cytol. 2004;240:31-304.

37. Boeynaems JM, Communi D, Gonzalez NS, Robaye B. Overview of the P2 receptors. Semin 
Thromb Hemost. 2005;31(2):139-149.

38. Meyts I, et al. IL-12 contributes to allergeninduced airway inflammation in experimental asthma. J Immunol. 2006;177(9):6460-6470.

39. Knorr B, et al. Montelukast, a leukotriene receptor antagonist, for the treatment of persistent asthma in children aged 2 to 5 years.
Pediatrics. 2001;108(3):E48

40. Howell WH, Donahue DD. The production of blood platelets in the lungs. J Exp Med. 1937;65(2):177-203.

41. Campbell EM, Kunkel SL, Strieter RM, Lukacs NW. Temporal role of chemokines in a murine model of cockroach allergen-induced airway hyperreactivity and eosinophilia. JImmunol. 1998;161(12):7047-7053.

42. Liu T, et al. Prostaglandin E2 deficiency uncovers a dominant role for thromboxane A2 in house dust mite-induced allergic pulmonary inflammation. Proc Natl Acad Sci U S A. 2012;109(31):12692-12697. 